\title{
واقع الخدمات الإرشادية التي يقدمها المرشد التربوي للطلبة الموهوبين والمتفوقين يِ المدرسة الحكومية الأردنية
}

$$
\text { وزارة التربية والتعليم، الأردن }
$$

\author{
سعاد منصور غيث

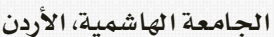

\author{
* سهيلة محمود بنات \\ جامعة عمان العربية، الأردن
}

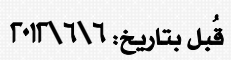

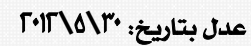

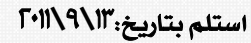

هدفت الدراسة إلى معرفة واقع الخدمات الإرشادية التي يقدمها المرشد للطلبة الموهوبين والمتفوقين فِ المدرسة الحكومية الأردنية، وكذلك التعرف على أثر بعض المتغيرات الديهوغرافيه على تقديم تلك الخدمات. ولتحقيق أغراض الدراسة قام الباحثون

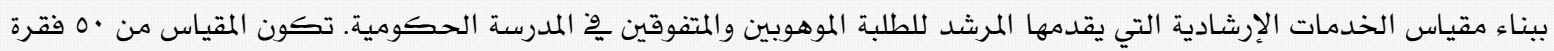
تقيس المجالات النفسية والأكاديمية والمهنية والأسرية والاجتماعية والمعرفية. تم تطبيق الأداة - بعد استخراج دلالات صدق وثبات

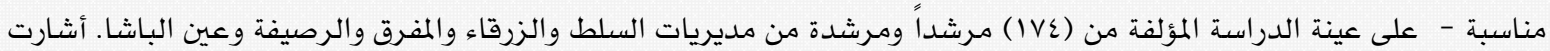
نتائج الدراسـة إلى أن المرشدين والمرشدات يمارسون الخدمات الإرشادية بشكل عام بدرجة منخفضة. كما أظهرت النتائج وجود فروق قو تقديم الخدمات الإرشادية للطلبة الموهوبين والمتفوقين تبعا لمتغير سنوات الخبرة وذلك لصالح المرشدين والمرشدات الذين تقل سنوات خبرتهم عن خمس سنوات، ولم تظهر فروق ذات دلالة إحصائية يٌْ درجة مهارسة تلك الخدمات تبعا لمتغيرات: الجنس، والمؤهل العلهي، ونوع المدرسة، وعدد الطلبة وِّ المدرسة. ويخ ضوء تلك النتائج قدمت توصيات بأهمية توعية وإعداد المرشدين والمرشدات

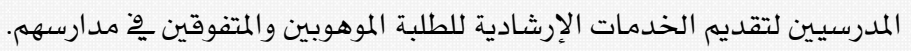
الكلمات المفتاحية: الخدمات الإرشادية، المرشد التربوي، الطلبة الموهوبين والمتفوقين، المدرسة الحكومية الأردنية.

\section{The Reality of Counseling Services Provided by the School Counselor for G ifted and Talented Students in the Jordanian G overnment School}

\author{
Sohaila M. Banat* \\ Soua'd M. Ghaith \\ Amman Arab University, Jordan HashemiteUniversity, Jordan \\ Mouhamed Sayel Barahmeh \\ Ministry of Education, Jordan
}

This study aimed to investigate the reality of counseling services provided by the school counselor for gifted and talented students in the Jordanian governmental school. Also, it aimed to know the effects of some demographic variables. The researchers developed a scale for the counseling services that consisted of 50 items. The instrument included: psychological, academic, vocational, familial, social, and cognitive aspects. It was administrated after checking it's appropriate reliability and validity. The sample consisted of 174 counselors from Salt, Zarqa, Almafraq, Alrosaifa, and Ain Albasha directories in Jordan. The results showed that the counselors practicing low level of the counseling services. Also, the results indicated a significant difference in the counseling services provided to gifted and talented students due to theyears of the experience fevoring to the counselors with an experience less than five years. On the other hand, there were no significant differences due to gender, degree, type of school, and the number of the students. In light of these results the researchers recommended that training opportunities and enhanecement should be provided to the counselors who serve the gifted and talented students in public schools.

Keywords: counseling services, school counselor, gifted and talented students, Jordanian public school.

*dr.s_banat@yahoo.com 
مساعدة فنية متخصصصـة ، و نظام داعم منظم الخم

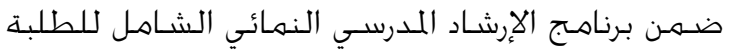

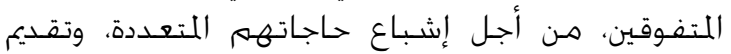

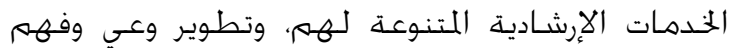

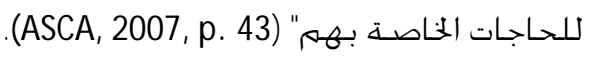

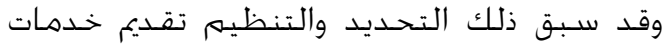

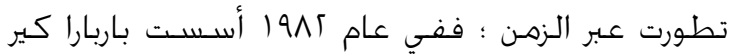
مـركزاً لتوجيه الموهوبين والمتفوقين في : (Barbara - Kerr)

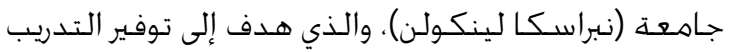

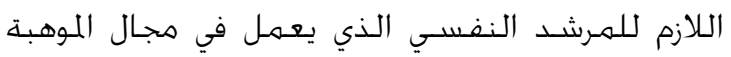

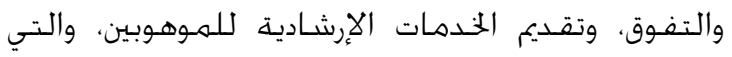

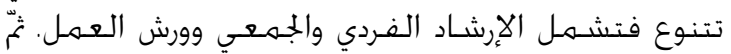

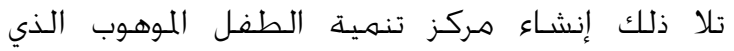

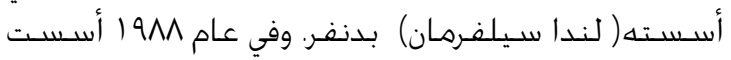

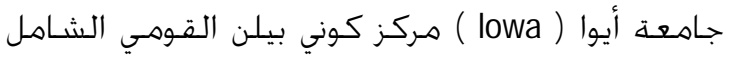

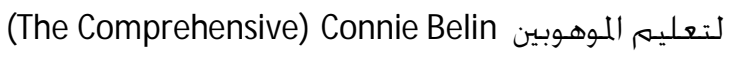
والذي ترأســ نيكولاس (National Center For Gifted) كولاجيلو. واهتع بالإرشـاد المهني للموهوبين والمتفوقين.

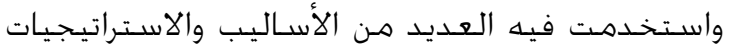

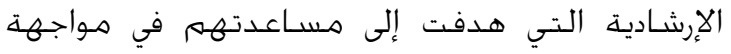

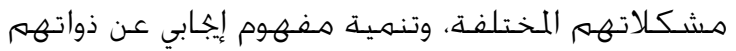

.(Colangelo, 2002)

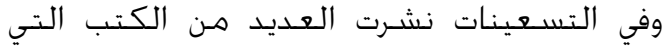
تناولت النمو الانفعالي والاجتماعي للطيلاب الموهوبين

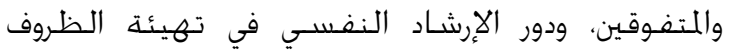

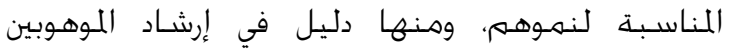

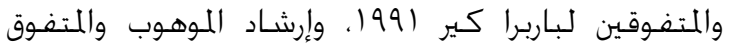

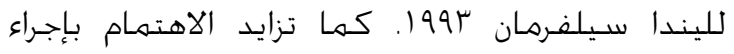

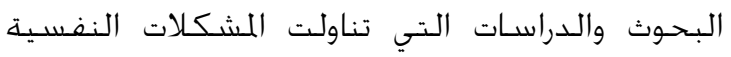

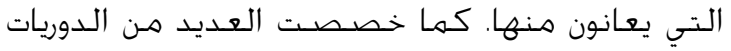

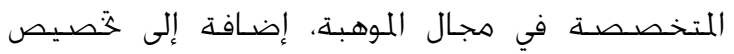

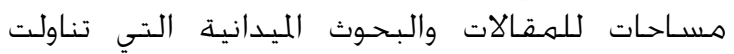

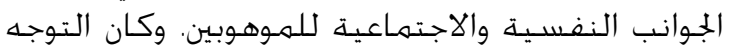

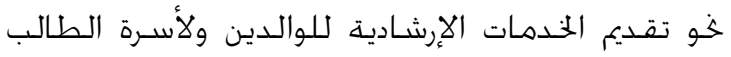

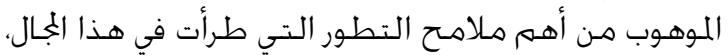

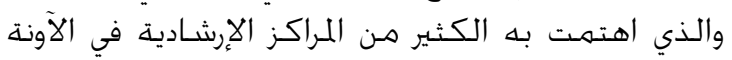

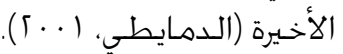

قامت الجمعية الوطنية الأهريكية للأطفال

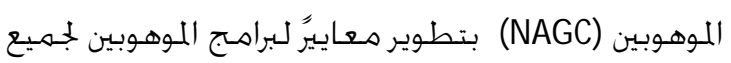

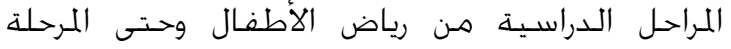

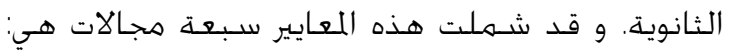

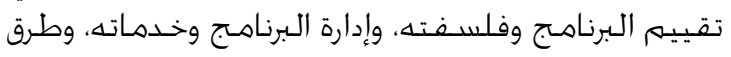

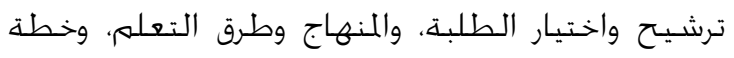

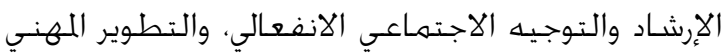

للقـائمسين على البرناهـج، وتقويم البرناهـج (Wood, 2010).
يمثل الطلبة الموهوبون والمتفوقون خدياً للمهرشـد

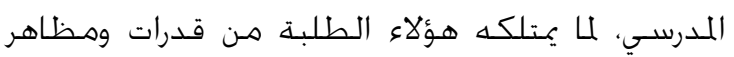

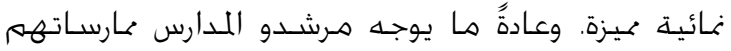

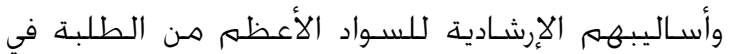

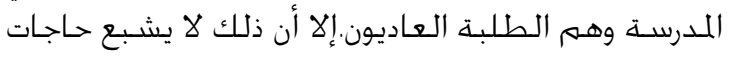

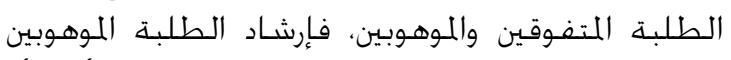

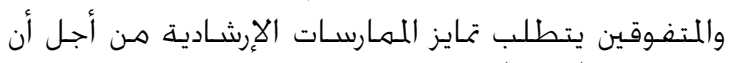

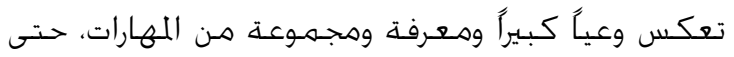

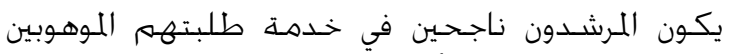

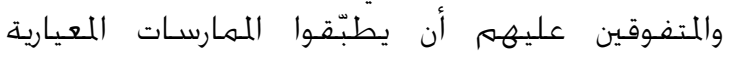
(Whiston \& Quinby, الأفضل للموهوبين والمتفوقين .2009; Wood, 2010)

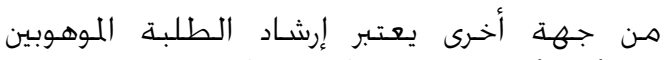

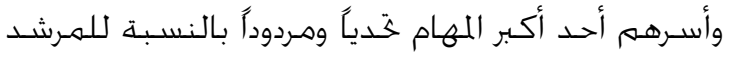

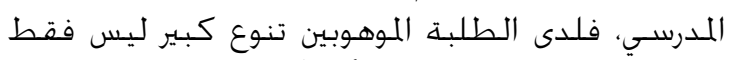

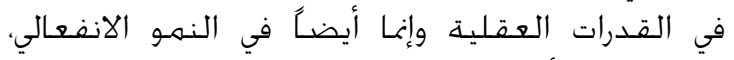

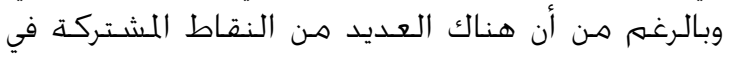

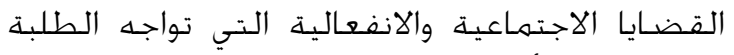

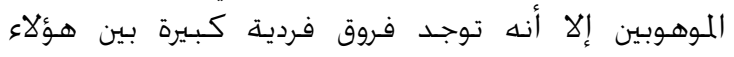

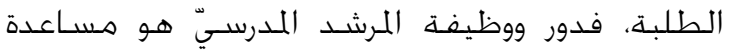

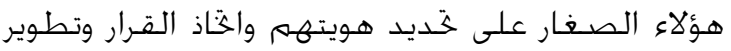

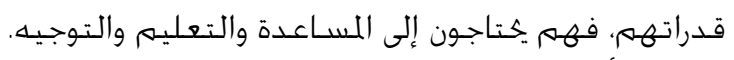

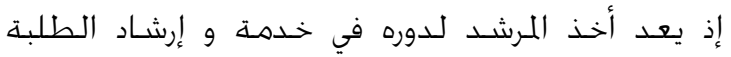

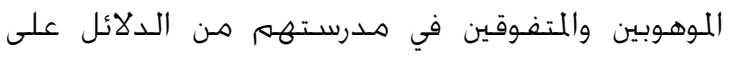

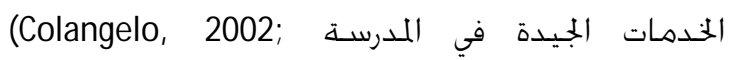

.(Peterson, Duncan \& Canady, 2009

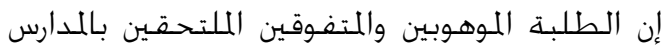

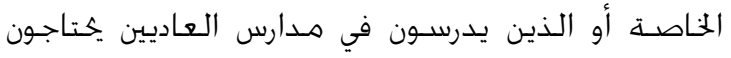

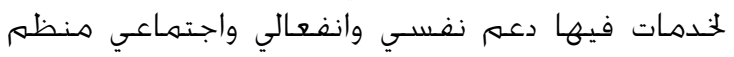

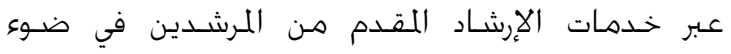

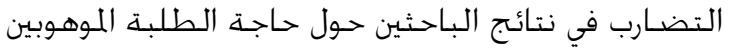

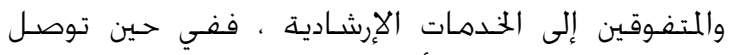

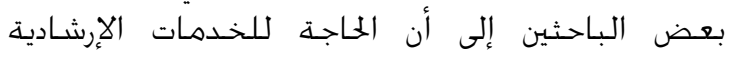

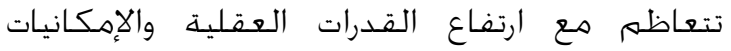
النفسية (Fouladchang, Kohgard \& Salah, 2010). فإن آخرين وجدوا أن الطلبة الموهوبين والمتفوقين عقليا

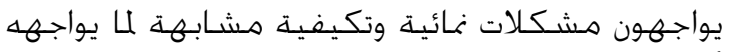

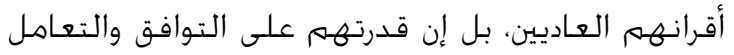

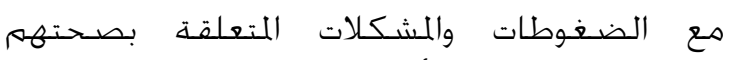
النفسية قد تكون أعلى لاستثمارهم إمكانياتهم المعهم Balilashak, Safavi \& Mahmoudi, ) الذهنية المرتفعة فكدة

2010

وقـد حـدّت جـمعية المرشـد المدرسيّ الأمريكية

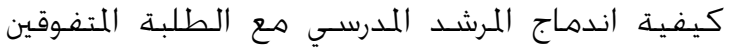

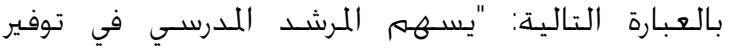


به من الأطفال يتمتعون بمستوى مرتفع من الإبداع لكن

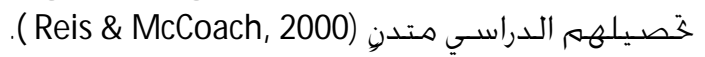

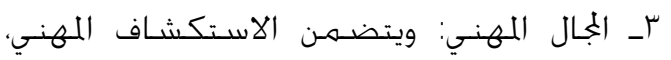

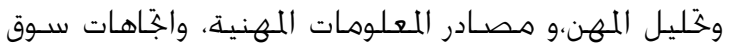

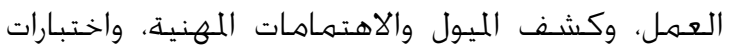

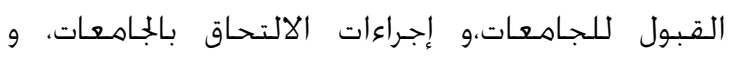

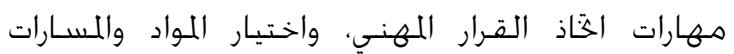

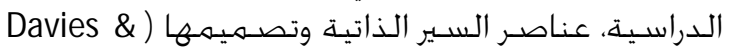
.(Rimm, 1998; Kerr \& Sodano, 2003; Watters, 2010

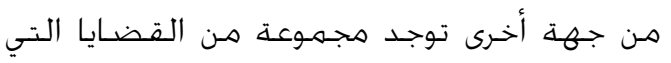

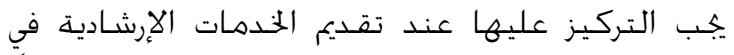
الجوانب (العـرفية والانفعالية والمهنية) اللذكورة سابقاً:

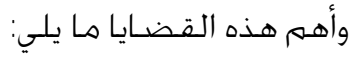

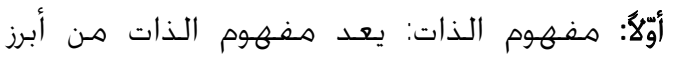

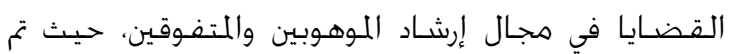

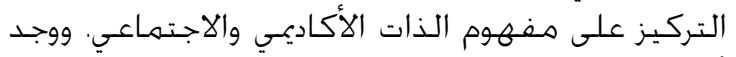

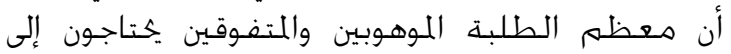

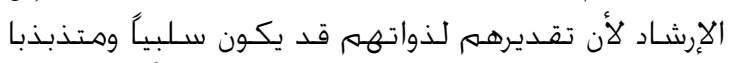

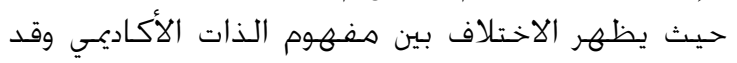

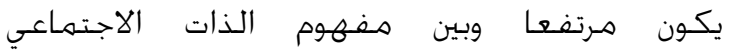

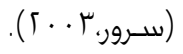

ثانبًا: تدنّي مستوى التحصـيل: ومن أهم المشكـلات التي قد يعاني منها الطلبة الموهوبين والمتفوقين التحنين

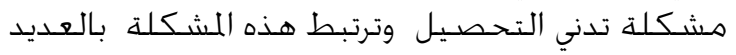

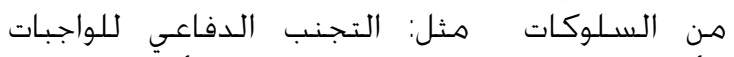

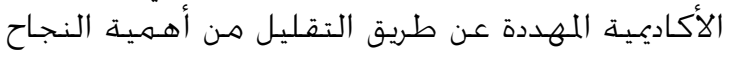

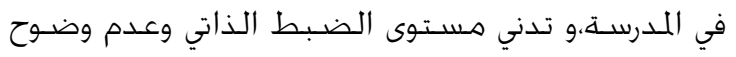

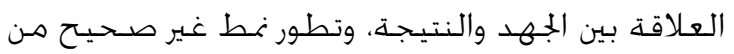

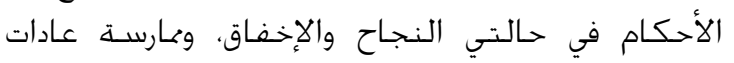

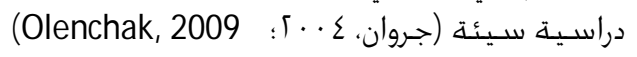

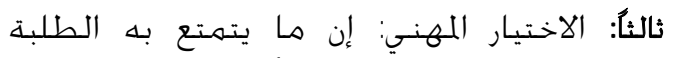

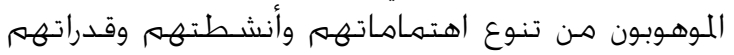

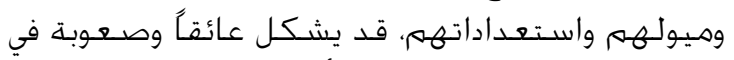

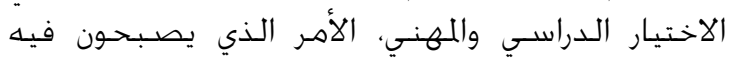

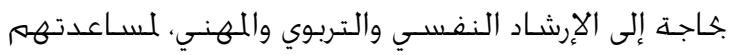

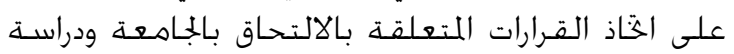

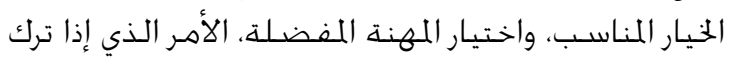

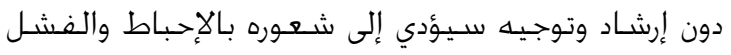

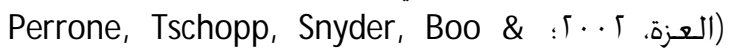

(Hyatt, 2010

ينبغي أن يمتلك المرشـدون خصائص أسـاسية المارية

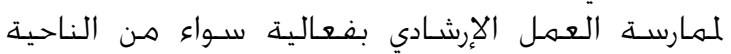

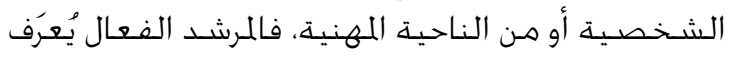

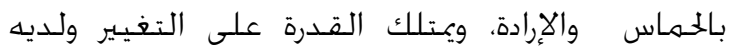

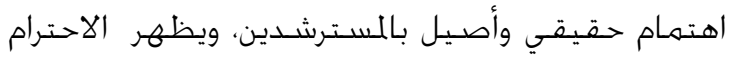

وسـنركز لغايات الدراسـة الحالية على الجمال الخامس

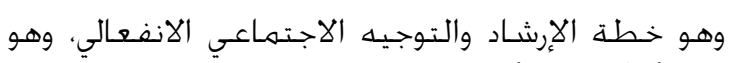

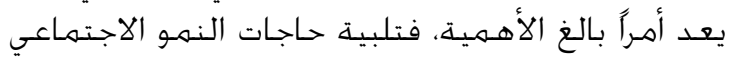

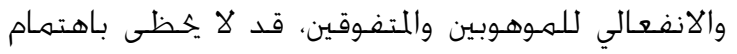

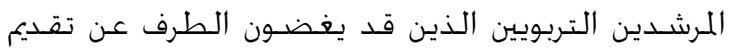

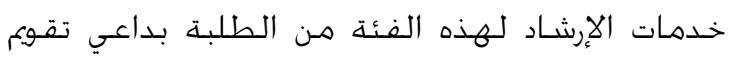

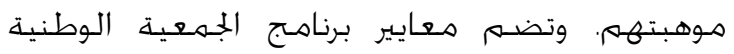

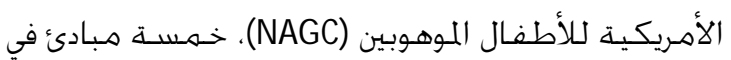
الإرشاد والتوجيه الاجتماعي الانفعالي وهي: للإنين

ا. ضرورة تزويد الطلبة الموهوبين بخدمات التوجيه

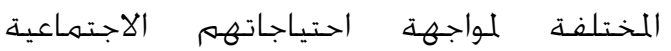
الانفعـالية.

r. أهمية تزويد الطلبة الموهوبين بخدمات التوجيه

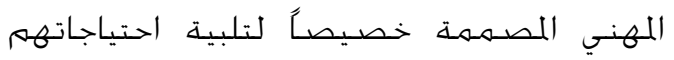

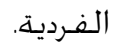

r. التأكيد على تزويد الطلبة الموهوبين المعرضين

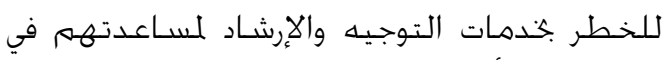
الوصـول إلى أقصى قدراتهمه.

ع. ضـرورة تزويد الطلبة الموهوبين بالمنهاج الانفعالي.

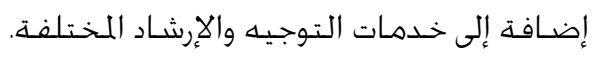

○. تقديم خدمات للطلبة الموهوبين ذوي الأداء المتدني

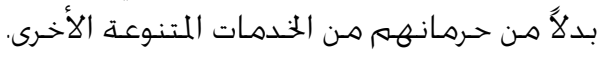

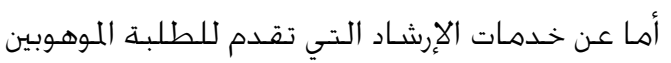

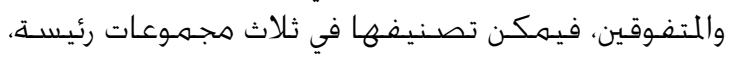

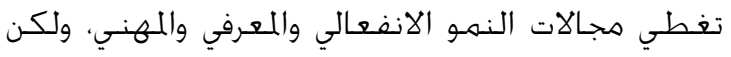

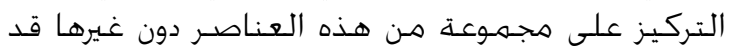

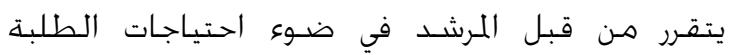

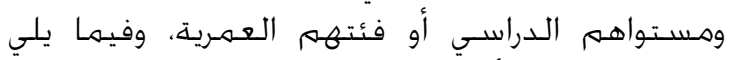

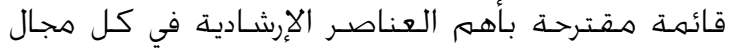

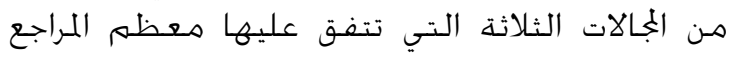
المتخصصة في علم نفس الموهبة والتفوق:

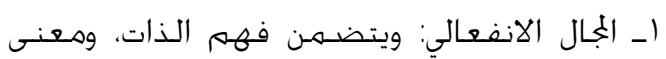

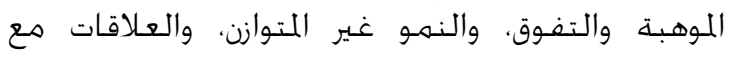

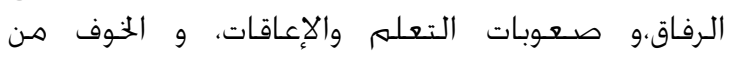

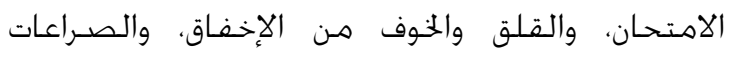

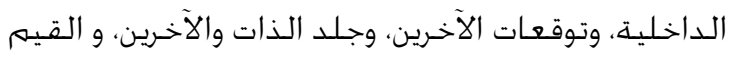

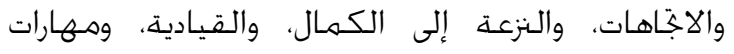

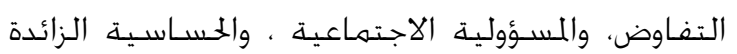

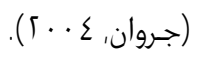

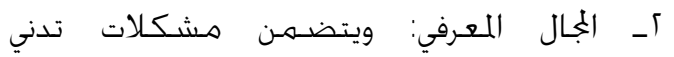

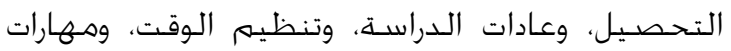

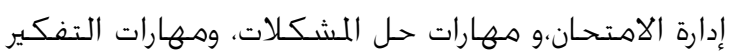

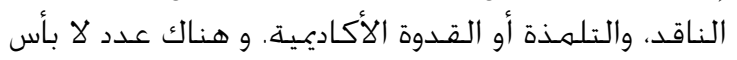


خاصة بهم ،و الخماضرات والمناقشات، والنادي الإرشادي.

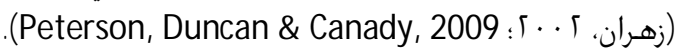

إن أساليب الإرشاد الفردي والجمعي المقدمة

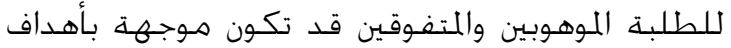
نمائية أو وقائية أو علاجية، ، ويكون الإرشاد بأهداف نمائية

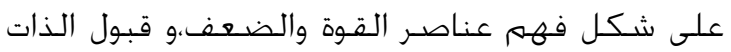

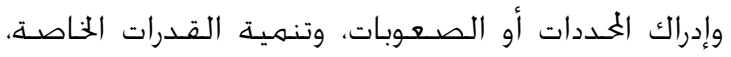

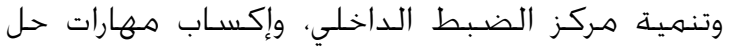

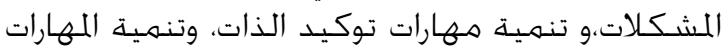

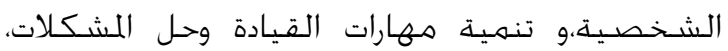

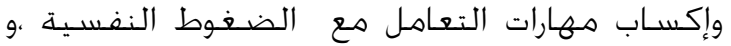
تنمية الاجّاهات الإيبابية خو أنفسهمه والآخرين والحياة

.( Peterson \& Lorimer 2011; Silverman, 1993)

أما الإرشاد الوقائي فقد قدم كابلن (Caplan) نمودجاً

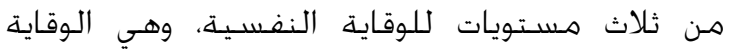

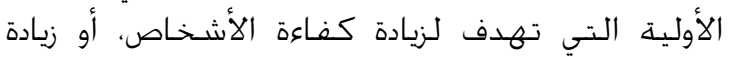

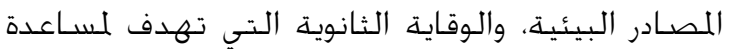

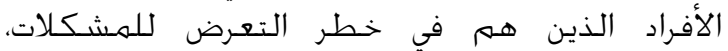

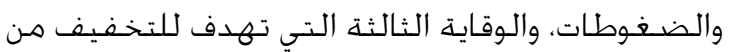
نتائج المشكلات والاضطرابات على الأفراد، وخسين اللخهن نوعية حياتهم وتعليمهـم مهارات اجتماعية.

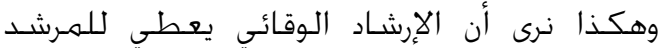

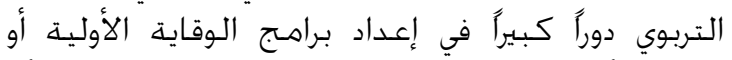

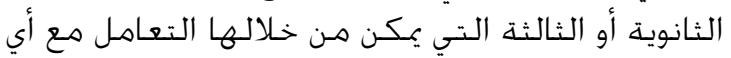

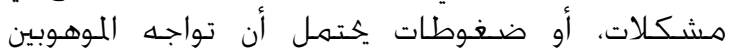

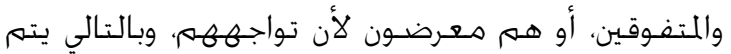

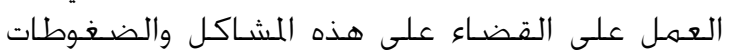

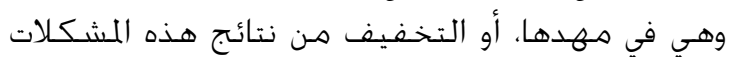

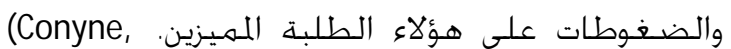

2004)

ومن الجدير بالذكر هنا الإشارة إلى تنامي التوجه خو الون

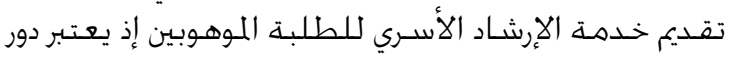

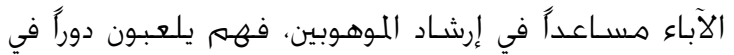

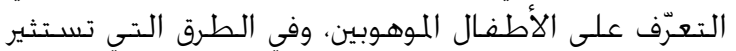

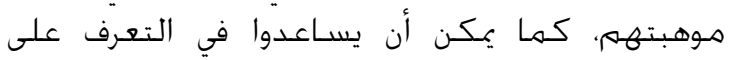

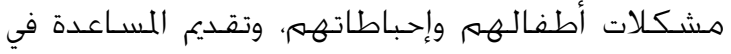
كيفية التعامل مع الضغوطات التهات التي يتعرضـون إليها. والإجابة عن التساؤلات التي يطرحونها والمتعلقة التهات

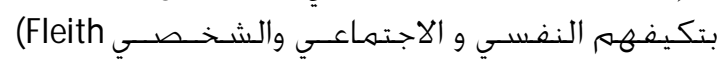
( \&uimarães, 2006) ويحتاج المرشـدون إلى إدراك أهـية الهية

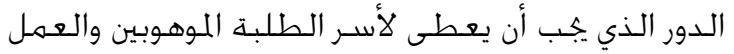

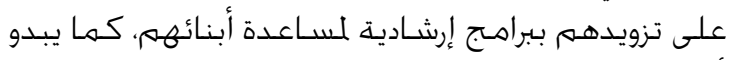

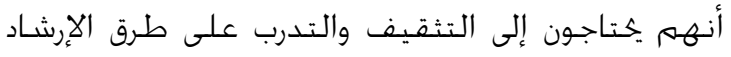

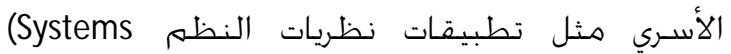

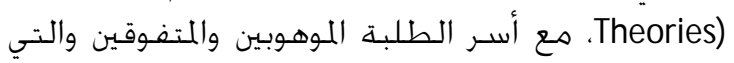

الايجابي غير المشـروط ، وإعطاء القيمة الحقيقية والايجابية

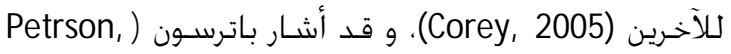

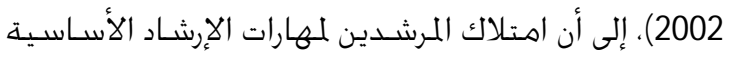

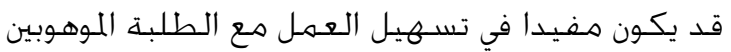

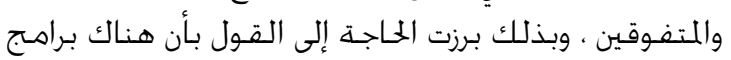

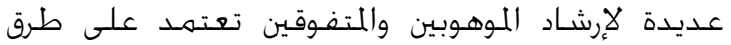

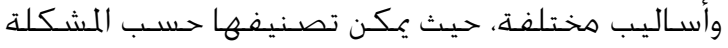

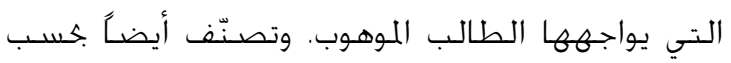

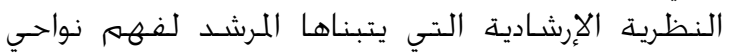

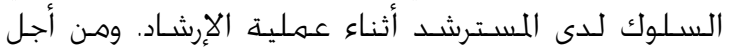

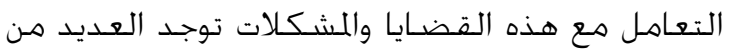

الأسـاليب والطرق الإرشادية لهؤلاء الطلبة ومنها:

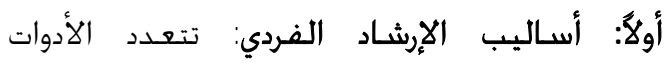
المستخدمة للإرشاد الفردي، ومنها:

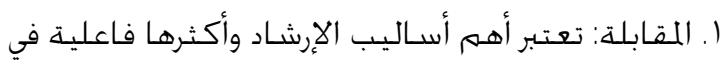

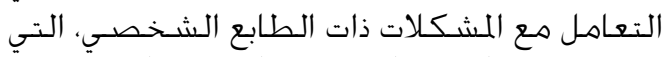

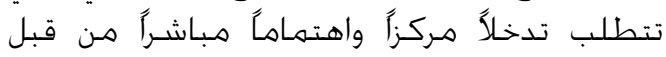

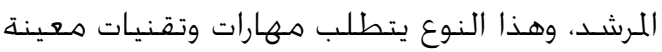

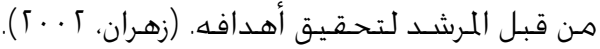

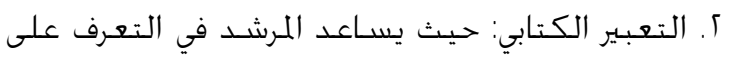

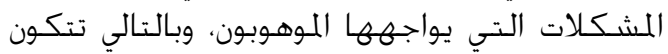

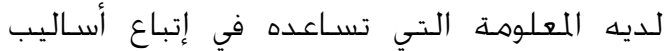

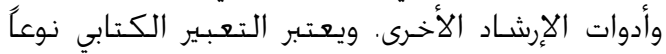

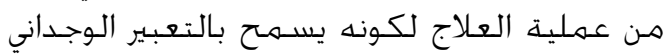

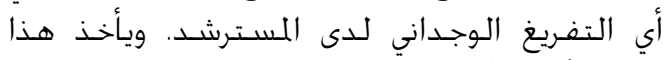

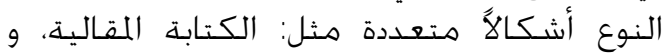

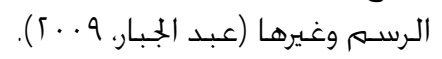

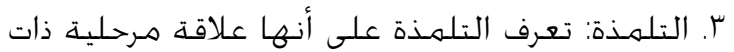

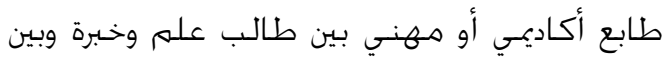

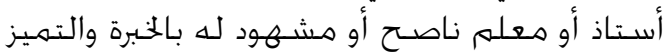

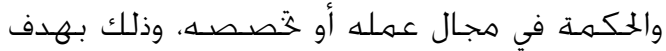
مسـاعدة المتعلم على استشـراف مستقبله المهاه المهني

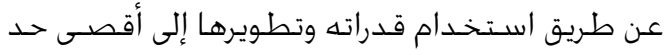

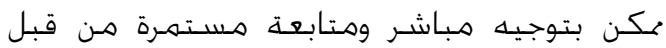

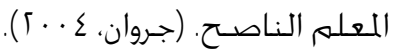

$$
\text { ثانيًا: أسـاليب الإرشاد الجمعي أجرون }
$$

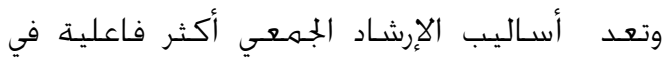

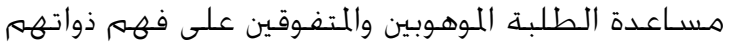

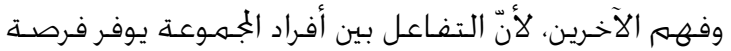

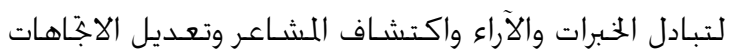

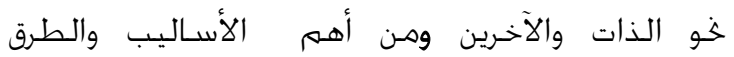

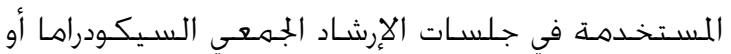

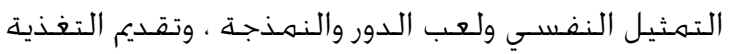

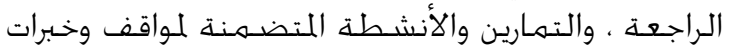




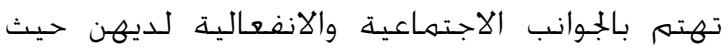
تفـقــر البراهـج اللقـدمة لمثل هذه الخدمات الإرشـادية.

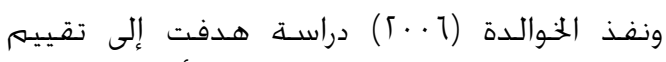

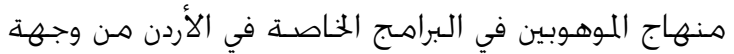

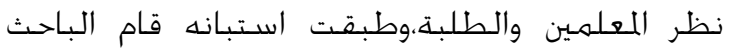

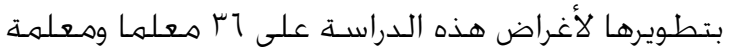

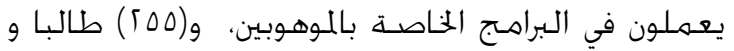

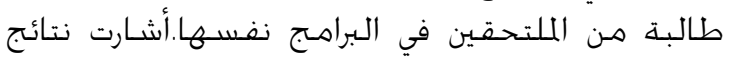

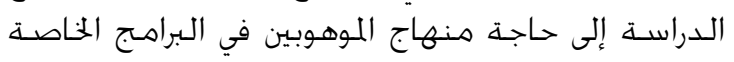

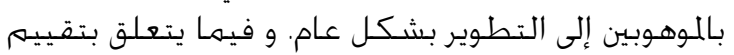

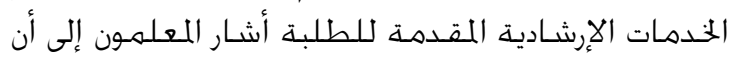

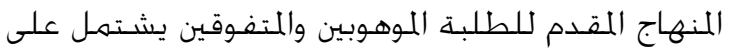

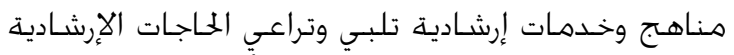

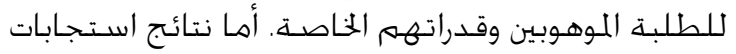

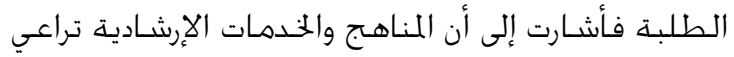

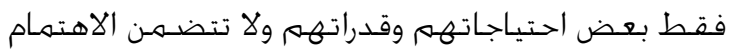
بكافة احتياجاتهمم النفسية واحتئه والانفعالية.

أمّا دراسـة الموهنـي (1 ؟) فهدفت إلى تقييـم براهـج

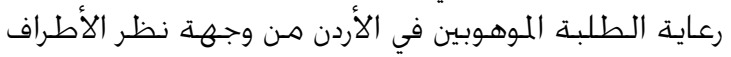

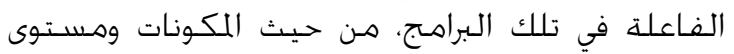

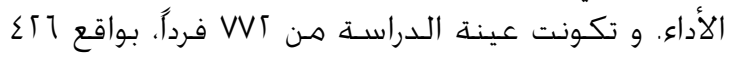

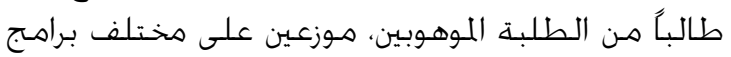

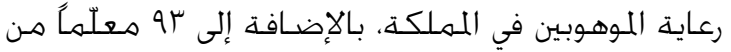

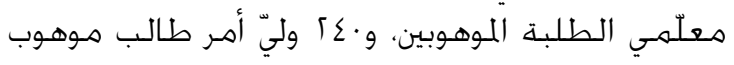

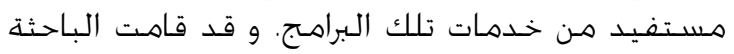

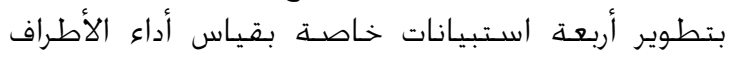

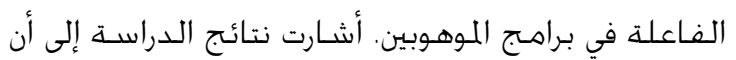

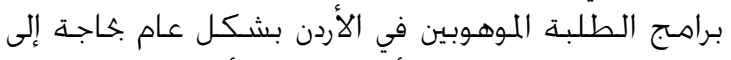

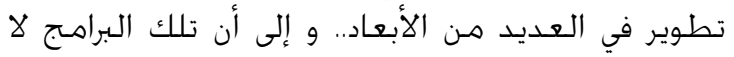

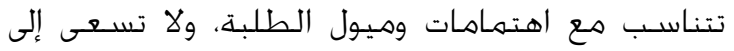

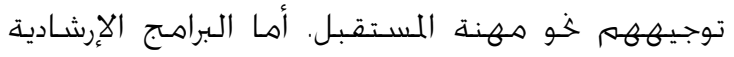

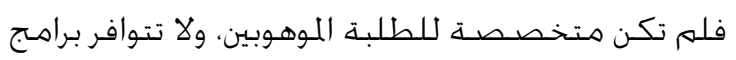

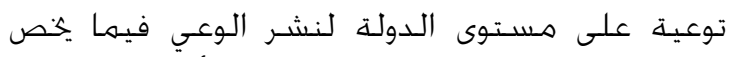

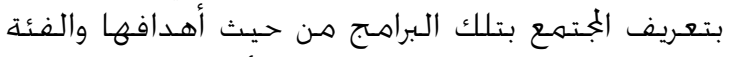

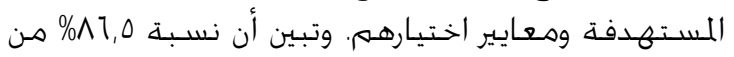

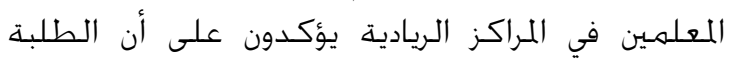

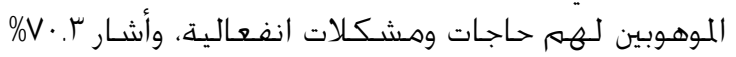

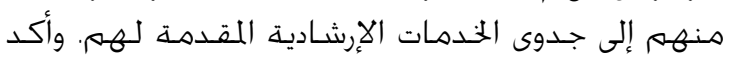

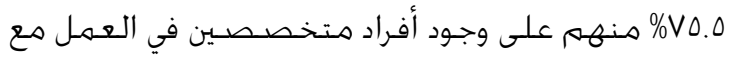

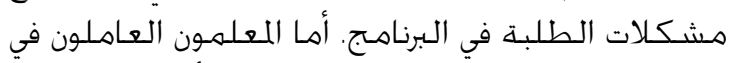

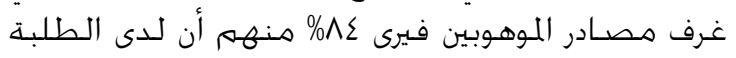

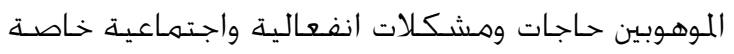

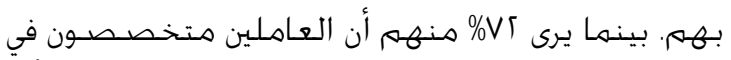

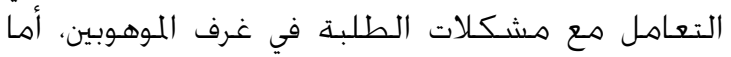

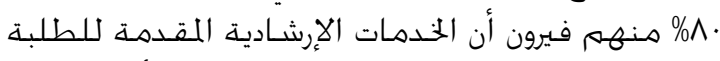

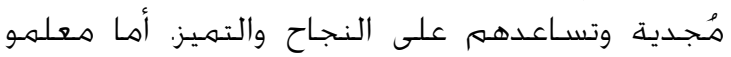

تأخــ بعين الاعتبار السياق الأكسبر الذي تظهر فيه

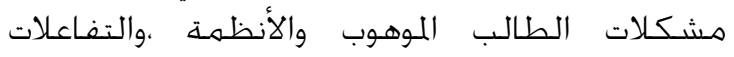

المتبادلة ما بين هذه النظم (Thomas \& Ray, 2006).

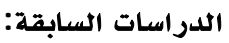

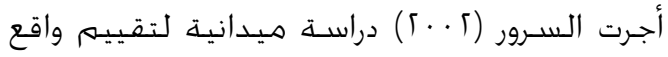

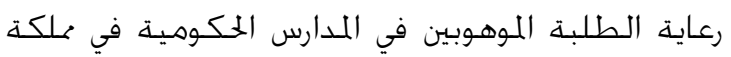

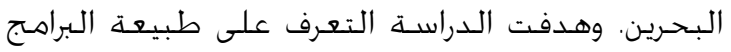

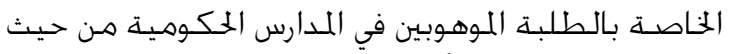

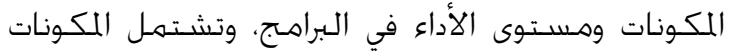

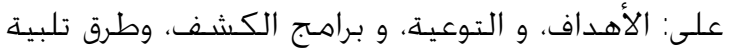

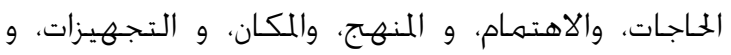

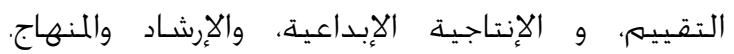

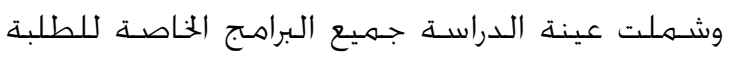

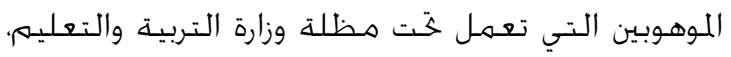

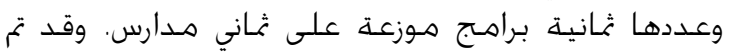

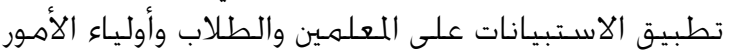

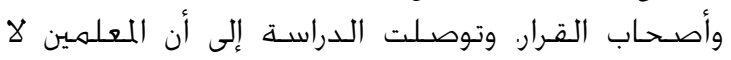

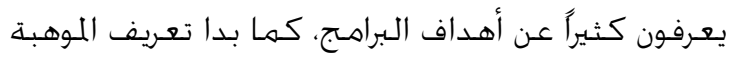

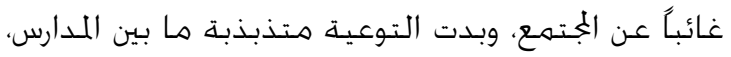

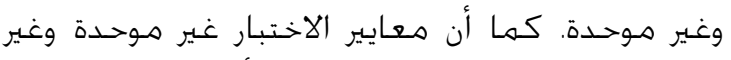

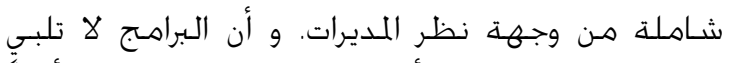

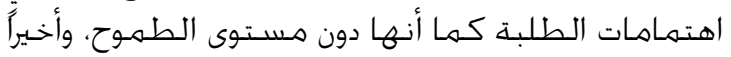

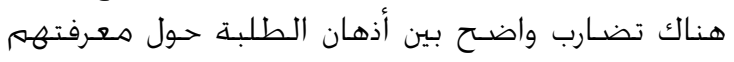
بالمنهاج الذي يتعلمهونه.

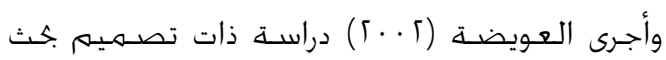

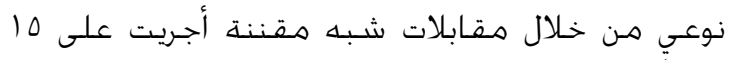

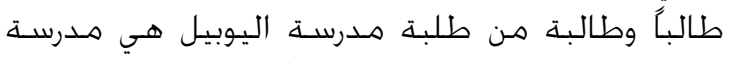

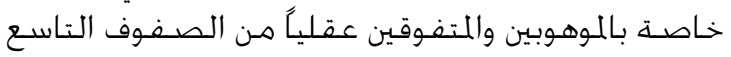

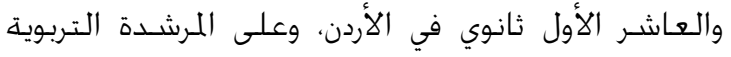

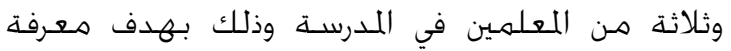

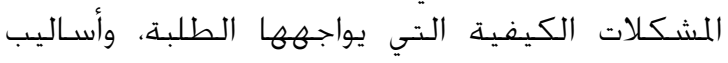

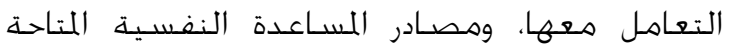

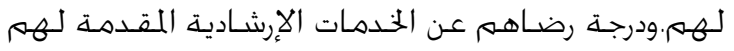

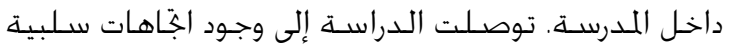

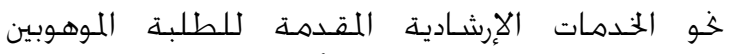

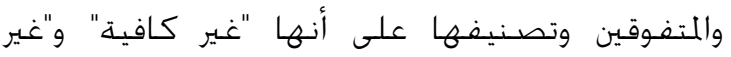

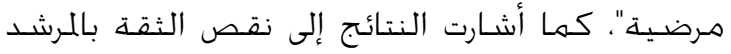
التربوي وقـدرته على المسـاعدة بفعـالية.

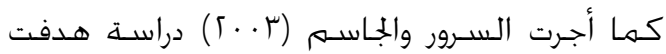

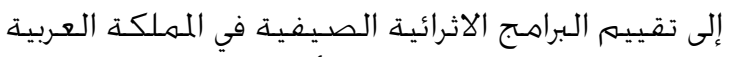

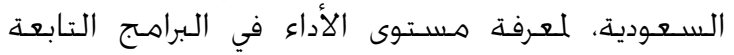

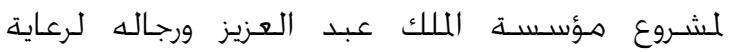

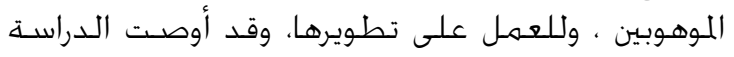

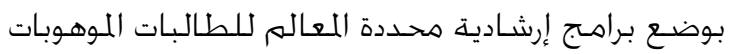


Wood, Torrel \& ( وقام كل من وود وتورل وكولاجنلو

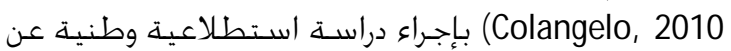

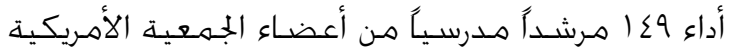

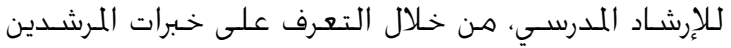

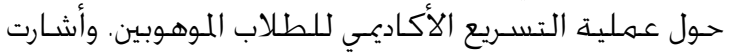

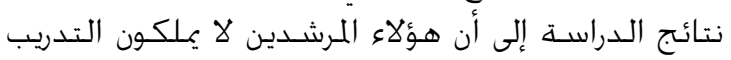

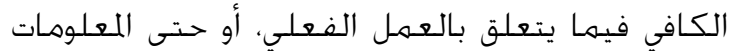

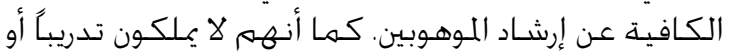

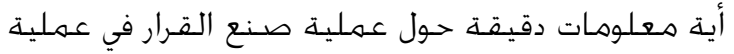

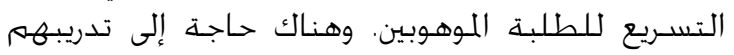

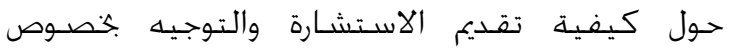

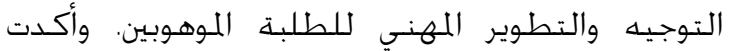

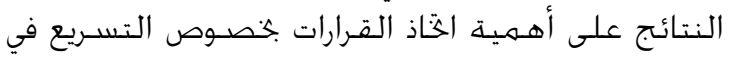
عملية التخطيط الأكاديمي للموهوبين، وضـرورة تركية تركيز

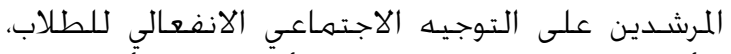

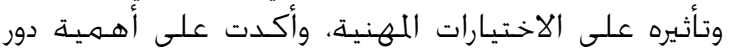

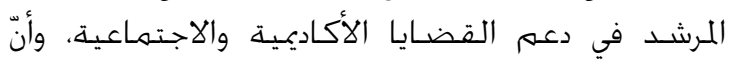

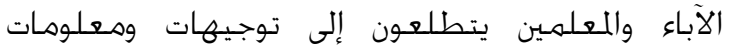

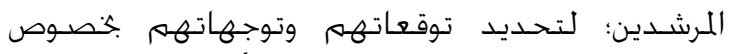

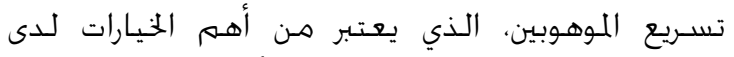

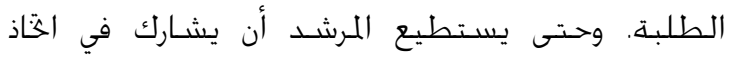

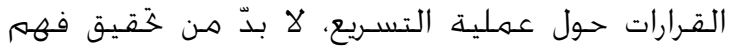

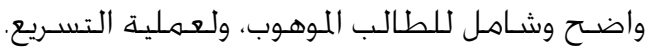

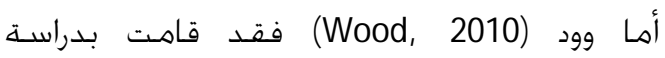

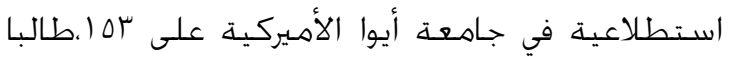

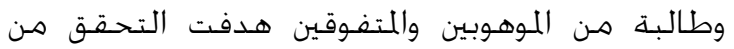
خبرات الشـباب المتفوقين والموهوبين حول خدمات الإرشياد

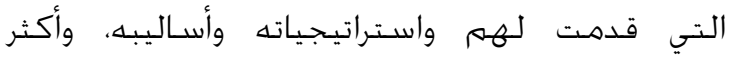

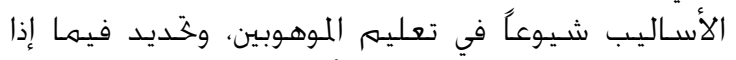

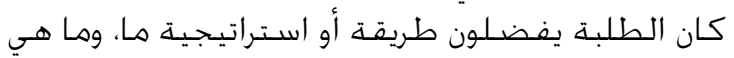

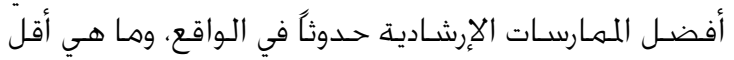

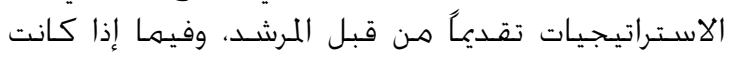

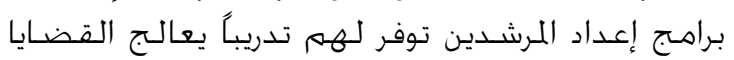

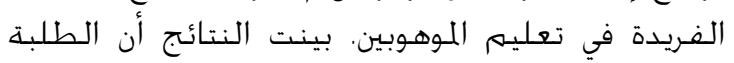

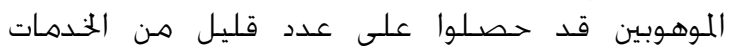

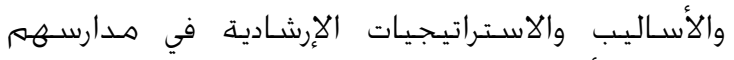

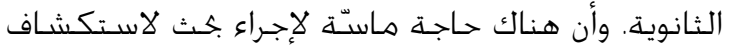

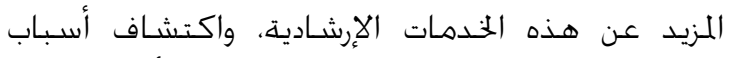

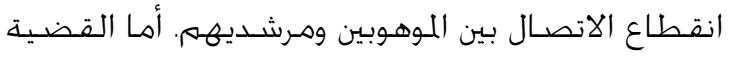

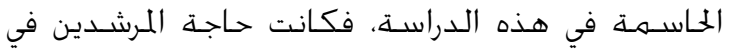

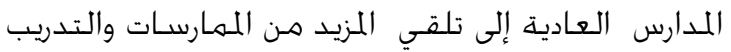
حول أسـاليب واستـراتيجيات الإرشاد العملية.

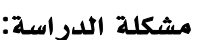

تنادي الاجّاهات الحديثة في البراهـج التربوية والمناهج

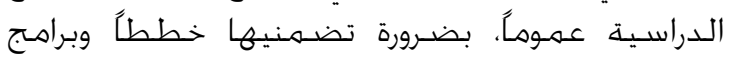
إرشادية لا تتجزأ عنها، ومساعدة الطلبة على فهم تهر

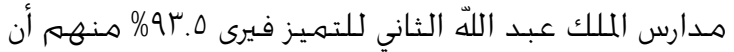

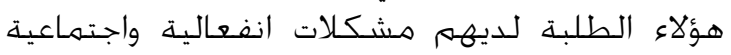

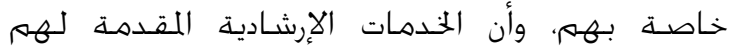

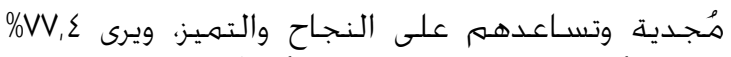

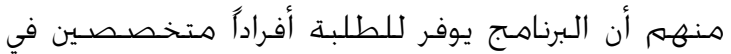

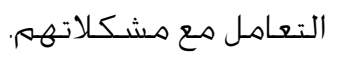

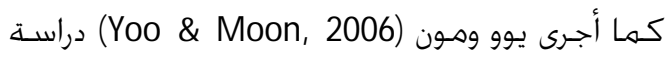

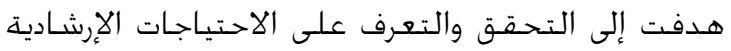

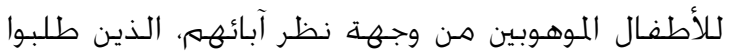

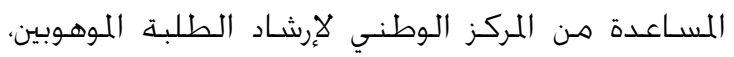

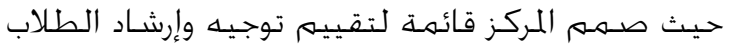

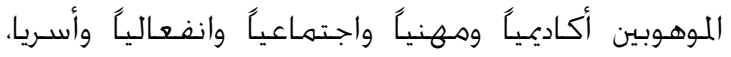

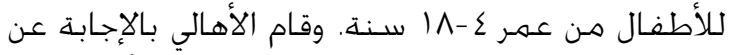

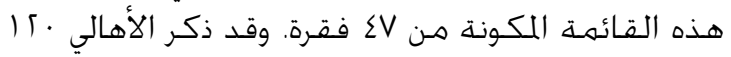

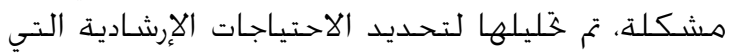

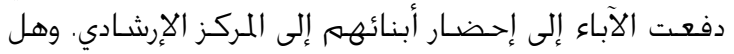

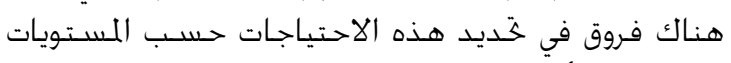

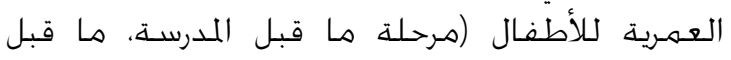

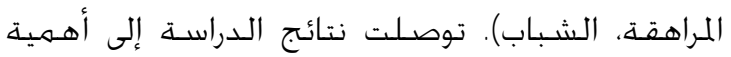

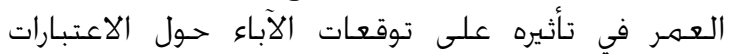

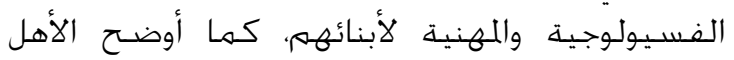

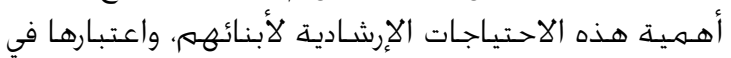

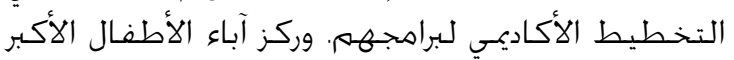

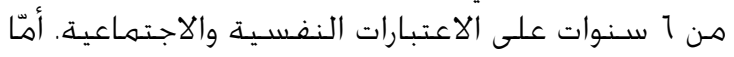

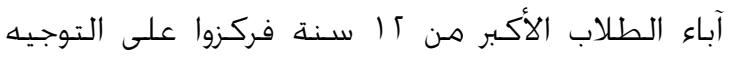

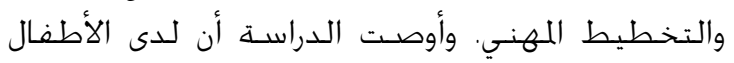

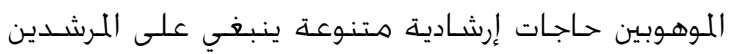

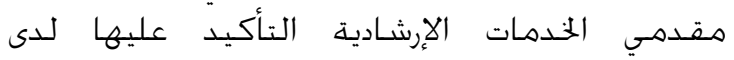

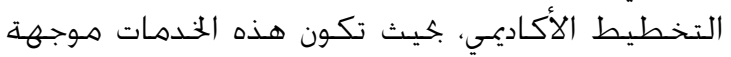
لتلبية احتياجات الموهوبين في مستويات النمو المختلفة. كما أجرت ايشاك وأبو بكر (Bshak \& Abu)

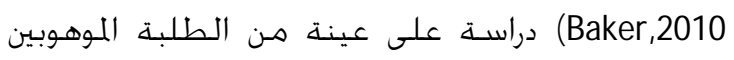

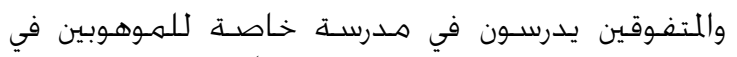

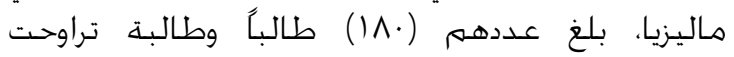

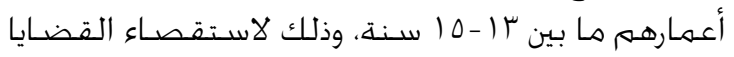

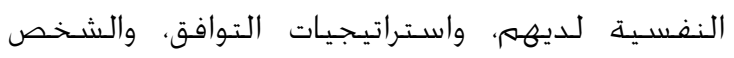

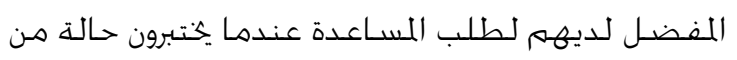

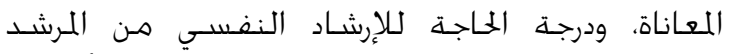

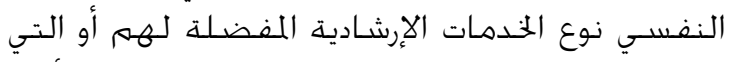

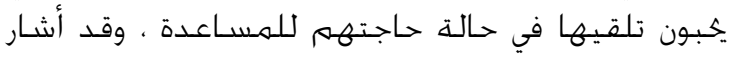

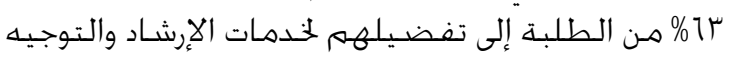

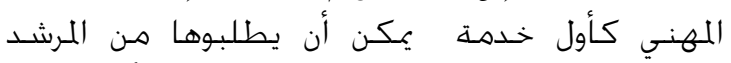

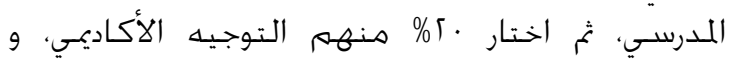

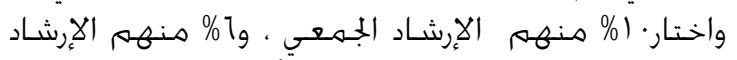
الفردي، و إ\% فقط اختاروا الإرشـاد الأســـي. 
يخضعون لأي من البراهـج الخاصـة الموجهة

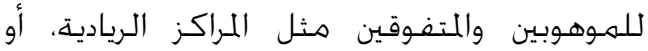

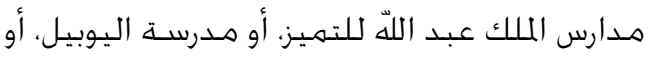
غرف المصادر الخاصـة بالطلبة الموهوبين والمتفوقين. • كذلك تبرز الأهـمية النظرية في تسـليط الضـوء

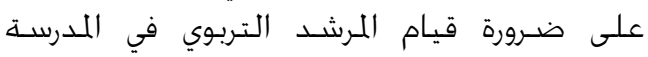

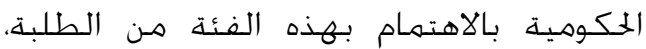

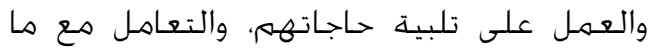

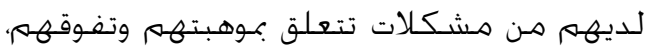

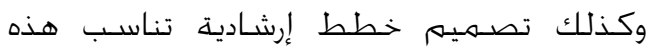

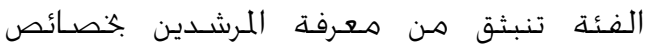
وحاجات وهشـكلات هؤلاء الطلبة معنة

\section{الأهـمية التطبيقية:}

• تمثل هذه الدراسـة أسـاسـا علميًا لأجحاث ودراسـات

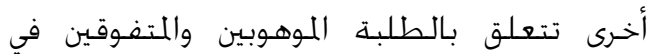

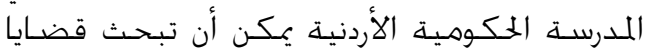

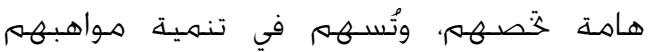
وإبداعاتهم: هامن.

• كذلك تكمهن أهـمية هذه الدراسـة في إمكانية توظيف نتائجها في وضع وتصـميهم خطط وبراهـج

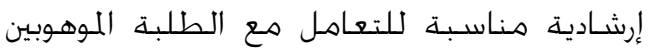
والمتفوقين المتواجدين في المدارس الحكـومية. • توفر هذه الدراسـة أداة يمكـن الاسـفـادة هـنه هـن قبل المسؤولين والمشـرفين على المرشـدين التربويين

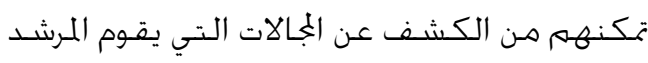

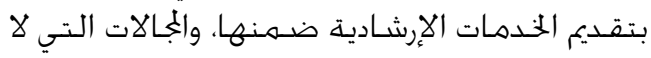

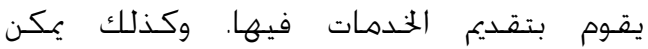

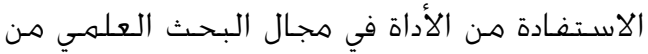

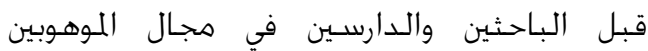
والمتفوقين.

• إن الاهتمام بفئة الطلبة الموهوبين والمتفوقين

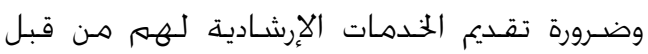

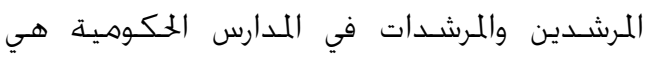

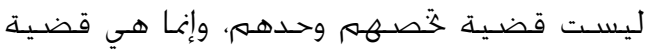

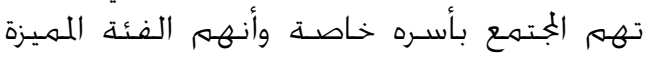

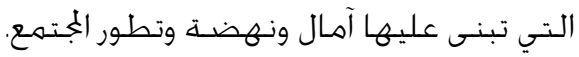

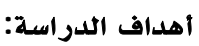

$$
\text { تهـدف الدراســة الحاليـة إلى: }
$$

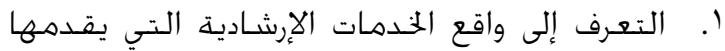

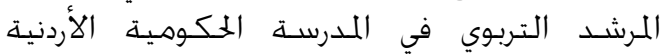

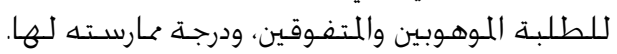
r ب. معرفة الفروق بين المرشـدين في تقديم الخدمات

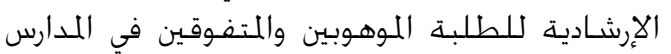

أنفسهـم والتغلب على مشكـلاتهم مالدراسية، والانفعالية، واكتشاف وإمكاناتهمه، واستثمارها،

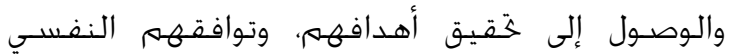

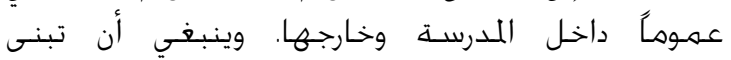

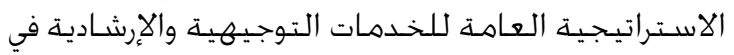

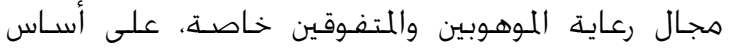

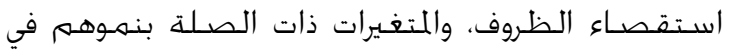

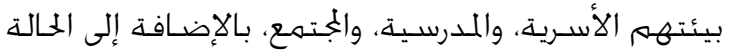

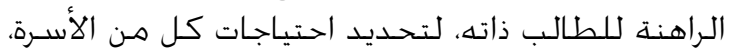

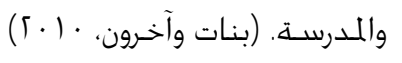

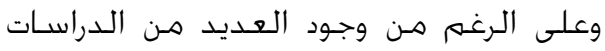

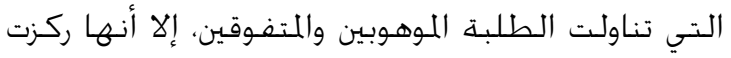

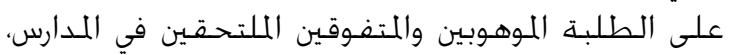

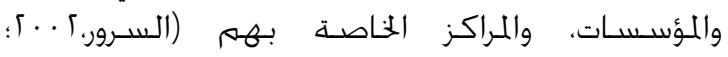

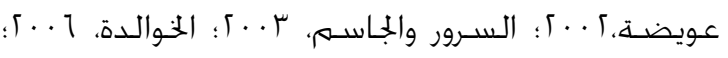

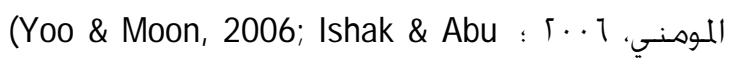
(Baker, 2010; Wood, 2010)

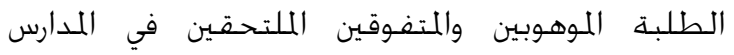

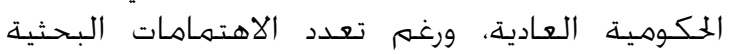

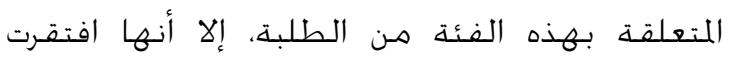

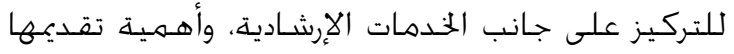

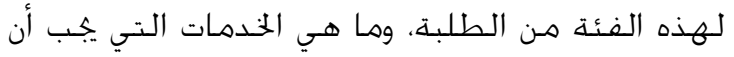

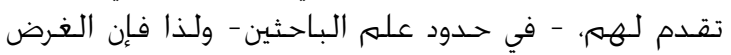

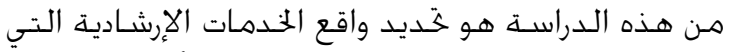

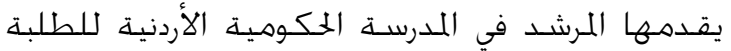
الموهوبين والمتفوقين.

\section{أسئلة الدراسة:}

خاول الدراسـة الإجابة عن الأسئلة التاليـة: 1- ما واقع الخدمات التي يقـدمها المرشـد التربوي

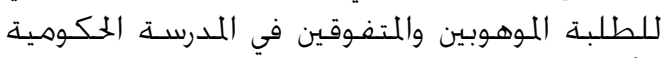
الأردنيـة؟ لمبلـ

r- - هل هنالك فـروق ذات دلالة إحصـائية، في الخدمات

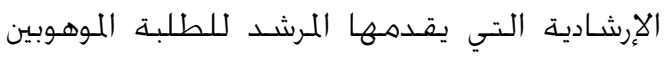

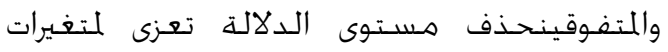

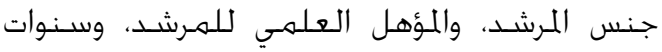

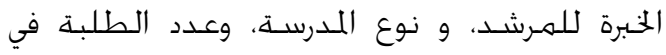
المدرسـة؟ الخبرة

أهمية الدراسة: يمكـن إظهـار أهـميـة هـذه الــراســة هـن خـلال مـا يأتي:

$$
\text { الأهـميـة النظرية: }
$$

• تكـمن الأهـمية النظرية للدراسـة الحالية في كونها

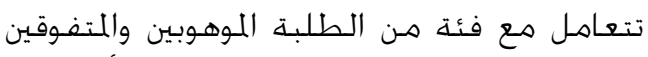

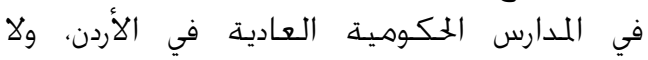


موهبة في أي هـن الجالات الثقافية، والعلمية،

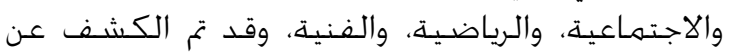

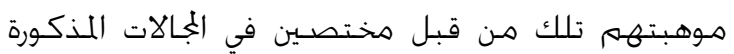
أعلاه.

المدرسـة الخكوهية: هي المدرسـة التابعة لوزارة

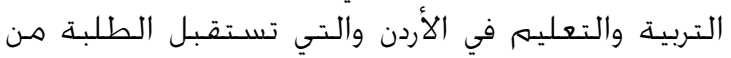

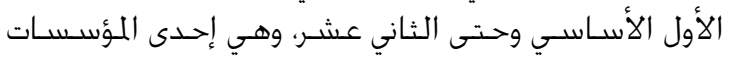

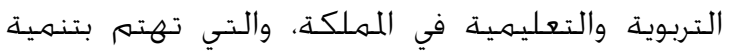

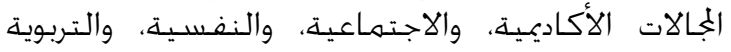

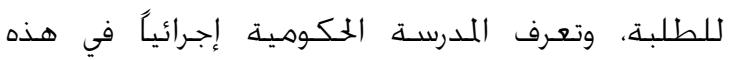

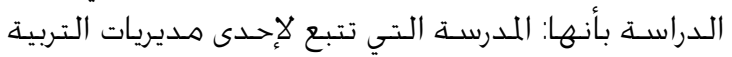

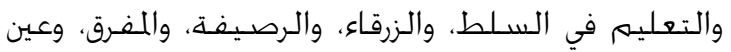

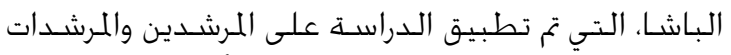

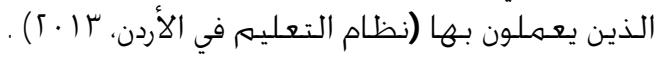

\section{الطريقة والإجراءات}

\section{مجتمع الدراسة:}

يتكـون مجتـمع الـراســة مـن جـميع المرشـدين

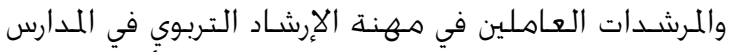

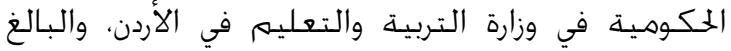

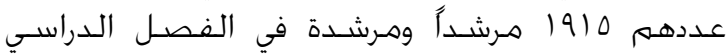

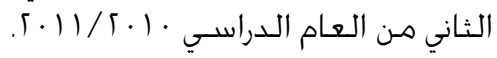

\section{عينة الدراسة:}

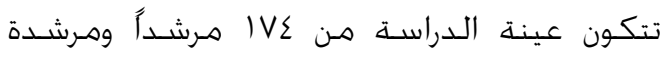
يعملون في المدارس الخكوهية في مديريات التربية

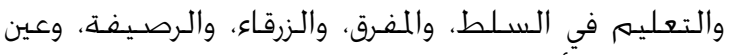

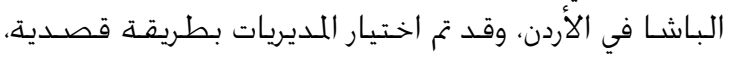

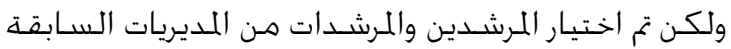
بطريقـة عشـوائية بسـيطة. ويوضسح جـدول ا توزيع عينة

$$
\text { الدراسـة حسب المتغيرات. }
$$

\section{جدول}

توزيع العينة حسب متغيرات الدراسة

\begin{tabular}{|c|c|c|c|c|}
\hline المجموع & & & & لمتغيرات \\
\hline \multirow[t]{3}{*}{ IV $\varepsilon$} & & إناث & ذكور & الجنس \\
\hline & & $|r|$ & or & \\
\hline & ماجستير & دبلوم & بكالوريوس & المؤهل \\
\hline \multirow[t]{2}{*}{$\mid V \varepsilon$} & 17 & 9 & $1 \leqslant 9$ & العلمي \\
\hline & أكثر من · 1 & منه -..1 & أقل من ه & سنوات \\
\hline \multirow[t]{2}{*}{ IV } & $\varepsilon \wedge$ & 09 & TV & الخبرة \\
\hline & اساسي وثانوي & ثنانوي & اساسي & نوع \\
\hline \multirow[t]{3}{*}{$1 V \varepsilon$} & זד & $\varepsilon r$ & 79 & المدرسة \\
\hline & اكثر من ... & من ...r - & أقل من & عدد \\
\hline & & $0 .$. & $r .$. & الطلبة \\
\hline $1 V \varepsilon$ & Nr & $\varepsilon$. & or & \\
\hline
\end{tabular}

الخكومية الأردنية، والتي تعود لمتغيرات الجنس، و

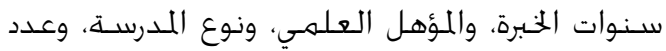

الطلبة.

\section{محددات الدراسة:}

يتحـدد تعـميم نتائج الدراسـة خارج مجتمعها

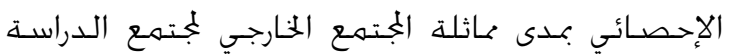

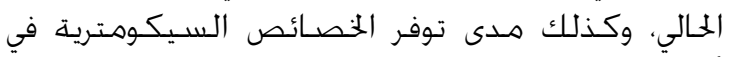

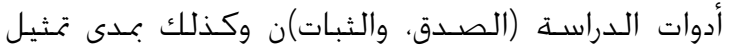

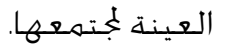

التعريفات النظرية والإجرائية للمص طلحات

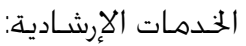

وهي مجموعة الأنشـطة والاســشـارات والإسـهامات

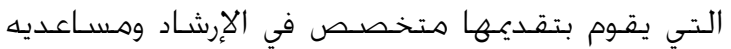

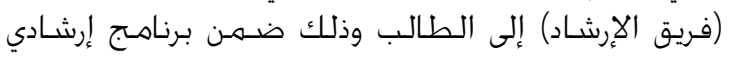

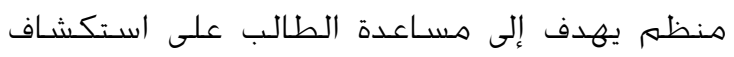

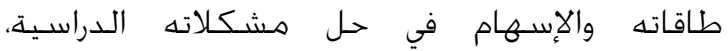

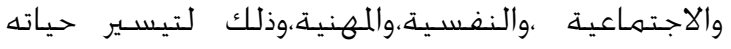

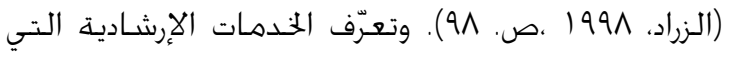

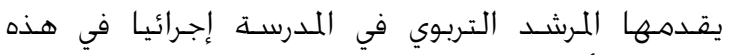

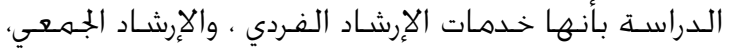

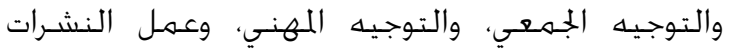

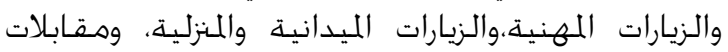

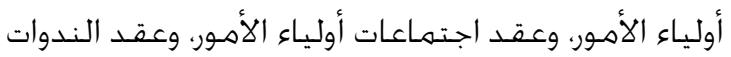
والغاضـرات.

المرشــــ التربوي: هـو الشـخص الذي درس الإرشـاد

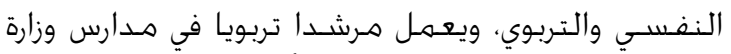

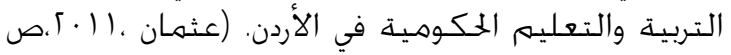

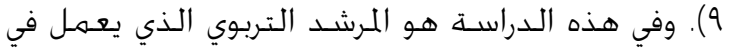

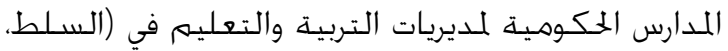
اللفـرق، الزرقاء، عين الباشـا) في الأردن.

الطلبة الموهوبون والمتفوقون: يعرف جروان (آ . ؟.

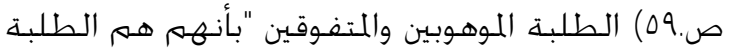

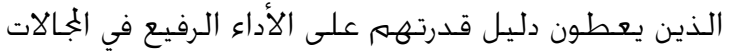

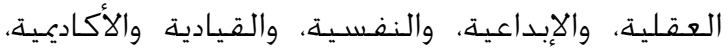

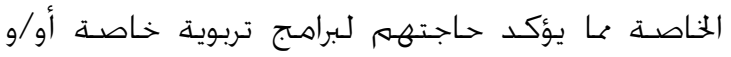

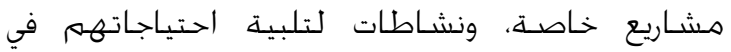

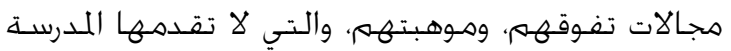

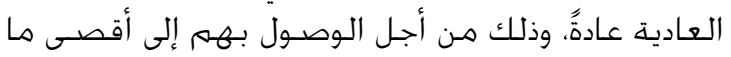

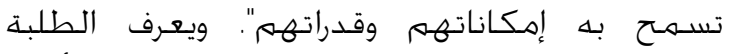

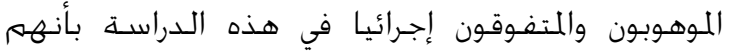

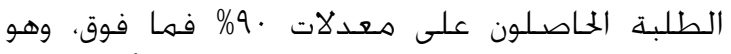

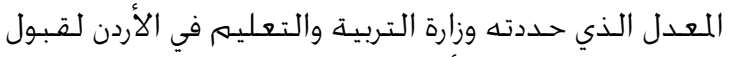

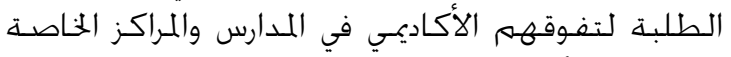

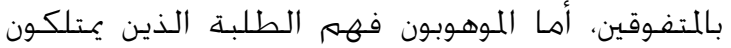




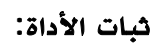

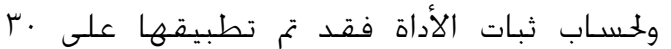

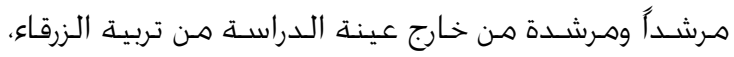

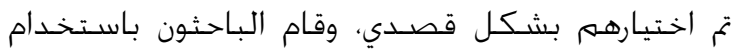

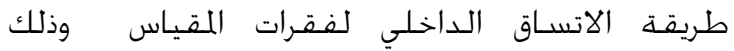

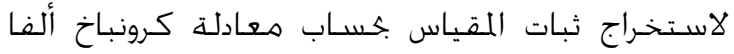

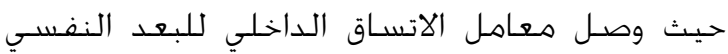

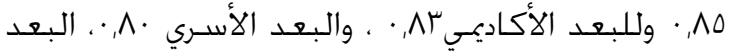

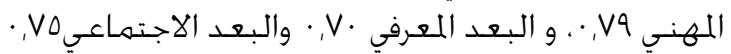

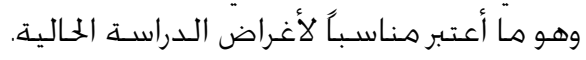

إجر اءات التطبيق:

قام الباحـثون بتطوير أداة الدراسـة، وهـن ثم اسـتخـراج

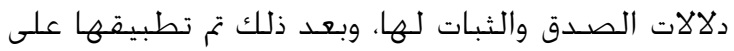

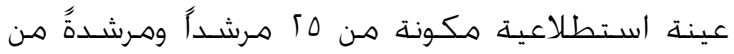

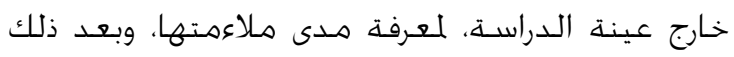

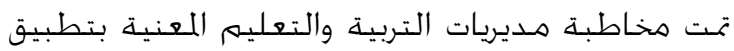

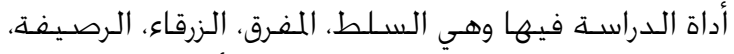

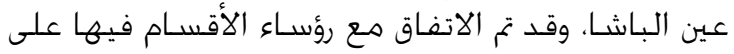

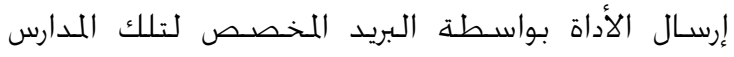

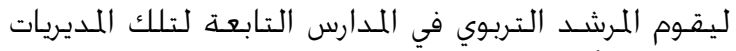

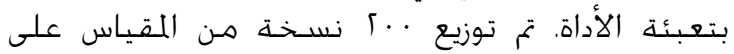

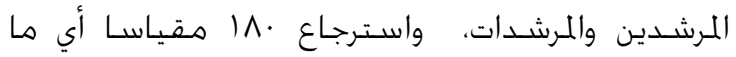

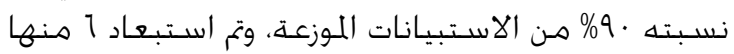

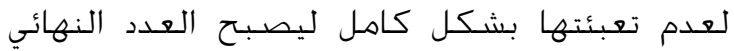

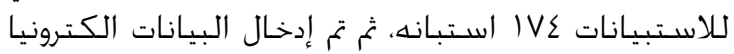

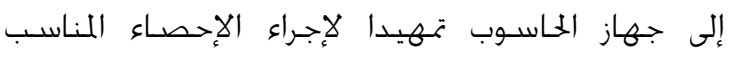
باستخــام الرزمة الإحصــائية للعلوم الاجتـماعية (SPSS).

\section{منهج الدراسة:}

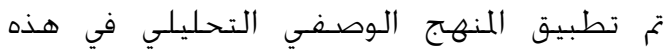

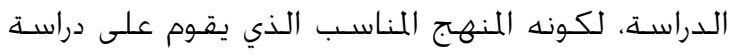

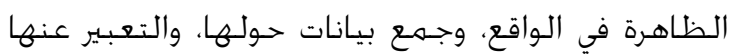

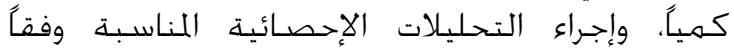

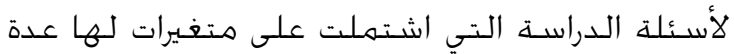

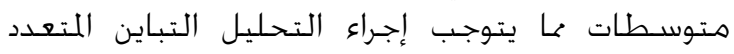

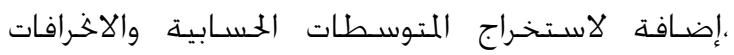
المعيارية والنسب المبئوية.

\section{نتائج الدراسة}

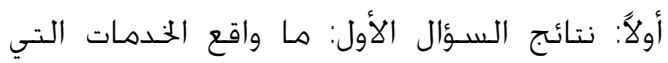

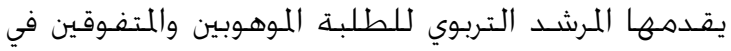

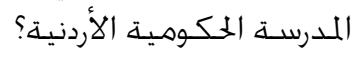

اسـتخـدمت الدراسـة مقياس الخدمات الإرشـادية

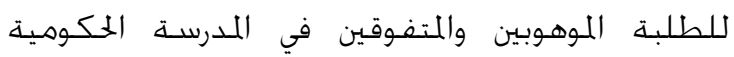
واللكون مـن ســـة أبعاد كمها سـيتضـح تالياً.

بناء المقياس:

تم بناء مقياس الخدمات الإرشادية للطلبـة الموهوبين

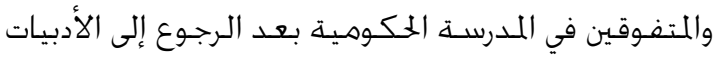

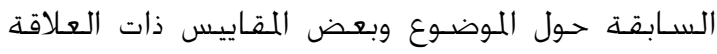
مثل مقياس وود (Wood, 2010)، ويتألف المقياس هن

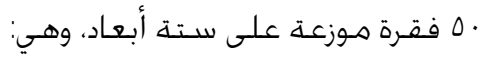

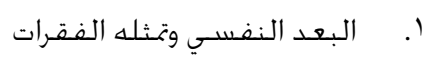

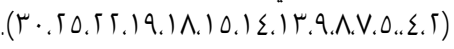

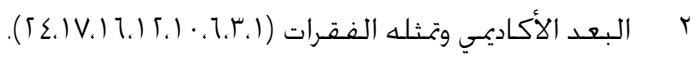

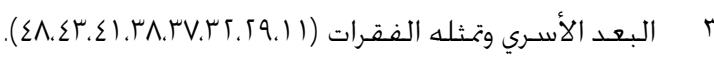

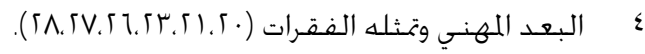

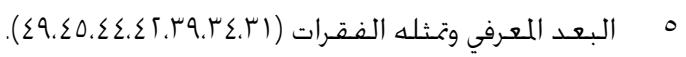

$$
\begin{aligned}
& 1
\end{aligned}
$$

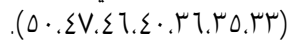

\section{صدق الأداة:}

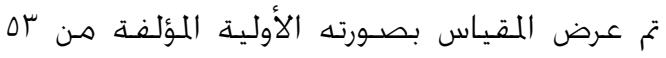

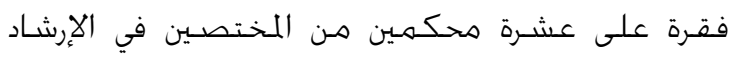

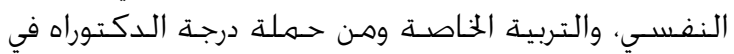

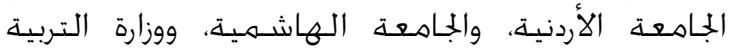

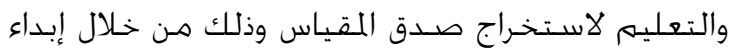

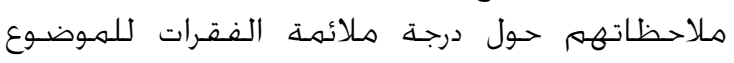

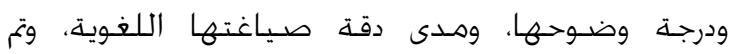

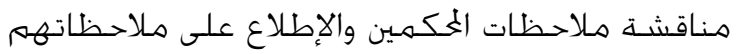

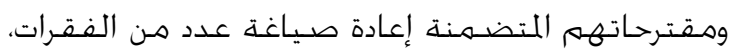

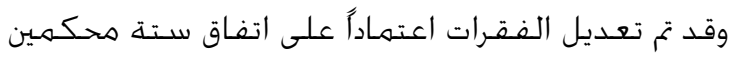

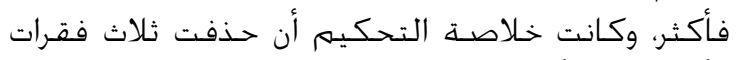

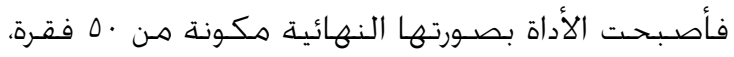

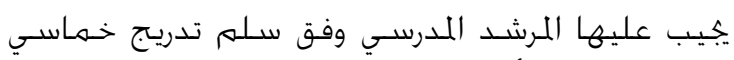

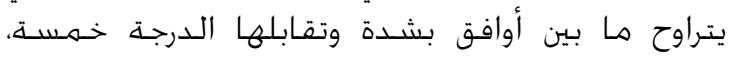

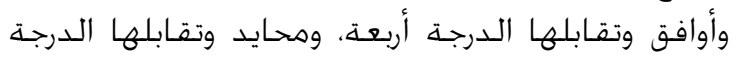

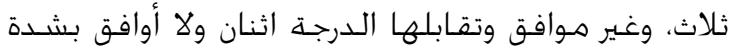

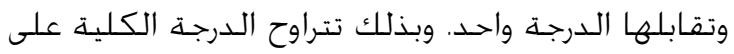

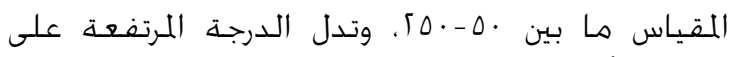

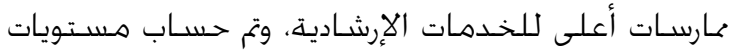
اللقياس وفقا للمعادلة الآتية:

$$
\begin{aligned}
& \text { ط }
\end{aligned}
$$

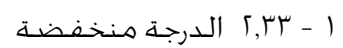

$$
\begin{aligned}
& \text { ع }
\end{aligned}
$$




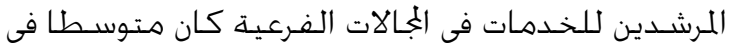

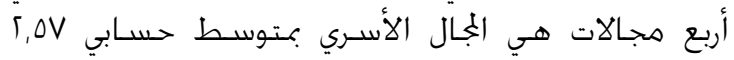

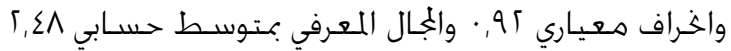

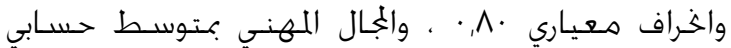
9r,

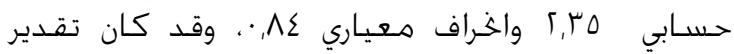

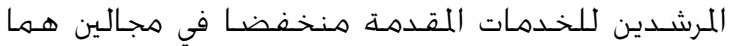

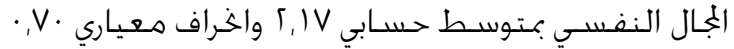

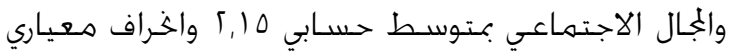
$\therefore, \mathrm{V} \mu$

ثانياً: نتائج السؤال الثاني: هل هنالك فروق ذات دلالة

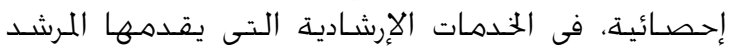

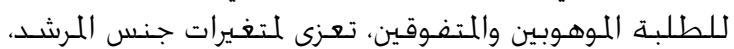

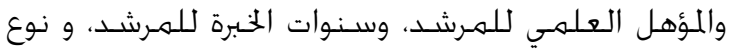

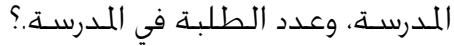

للإجابة عن سؤال الدراسـة الثاني تم حسـاب

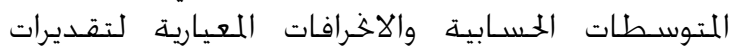

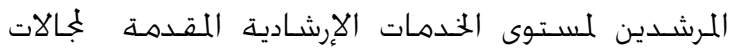

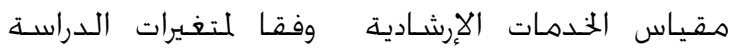

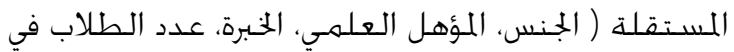

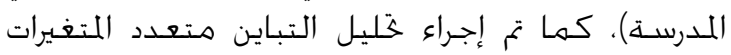

جدول ra

المتوسط الحسابي والانحراف المعياري لتقديرات المرشدين والمرشدات للخدمات الإرشادية المقدمة للموهوبين والمتقوقين في المدارس الحكومية المبرية

\begin{tabular}{|c|c|c|c|c|}
\hline مستوى & الانحراف & الحستوسط & المجال & الرق \\
\hline منخفض & $\cdot, \vee \cdot$ & r,IV & النفسي & 1 \\
\hline متوسط & $\cdot, \wedge \varepsilon$ & r,ro & الأكاديمي & r \\
\hline متوسط & $\cdot, 9 r$ & r.OV & الأسري & $r$ \\
\hline متوسط & $\cdot, \wedge \wedge$ & $r, r q$ & المهني & $\varepsilon$ \\
\hline منوسط & $\cdot, \wedge$. & $r, \varepsilon \wedge$ & المعرفي & 0 \\
\hline منخفض & $\cdot, \mathrm{VT}$ & $r, 10$ & الاجتماعي & 7 \\
\hline منخفض & $\cdot, V Y$ & r, r & الكلي & \\
\hline
\end{tabular}

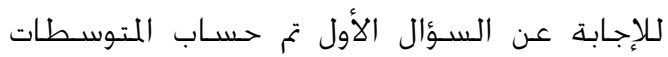

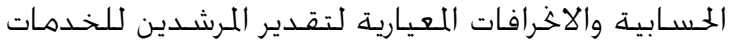

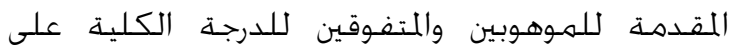

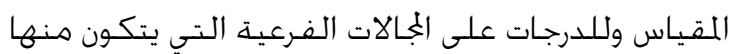
المقياس، وفيما يلي عرض لهذه النهات النتائج.

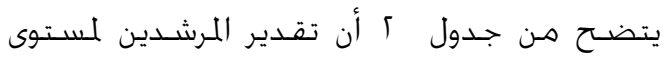

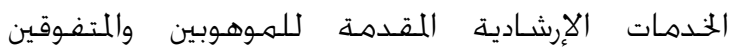

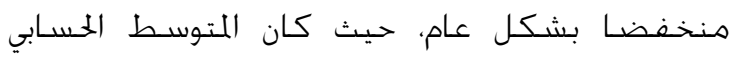

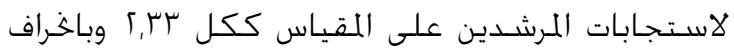

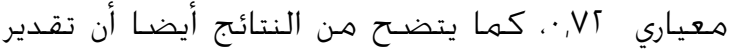

جدول ra rallo

المتوسط الحسابي والانحراف المعياري لتقبرات المرشدين للخدمات الإرشادية المقدمة للطلبة الموهوبين والمتفوقين في المدارس الحكومية وفقا لمتغيرات: الجنس، الخبرة،

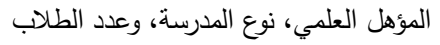

\begin{tabular}{|c|c|c|c|c|c|c|c|c|c|c|c|c|}
\hline \multirow[b]{2}{*}{$\varepsilon$} & \multicolumn{2}{|c|}{ الاجنماعي } & \multicolumn{2}{|l|}{ المعرفي } & \multirow{2}{*}{$\begin{array}{l}\text { المهني } \\
\text { ا }\end{array}$} & \multicolumn{3}{|c|}{ الأسري } & & \multirow{2}{*}{ فئات المتغير } & \multirow{2}{*}{ المتغير } \\
\hline & 5 & $\varepsilon$ & 5 & $\varepsilon$ & & $\varepsilon$ & 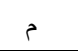 & $\varepsilon$ & 5 & العدد & & \\
\hline$\cdot, 00$ & $r, r)$ & $\cdot, 7 \varepsilon$ & $r, \Sigma V$ & $\cdot, T V$ & $r, \Sigma Y$ & $\cdot, \wedge \mathrm{V}$ & $r, 7 q$ & $\cdot, 00$ & $r, 1 \wedge$ & or & ذكر & \\
\hline$\cdot, \vee \vee 9$ & r,IT & $\cdot, \wedge \vee$ & $r, \varepsilon q$ & $\cdot, 97$ & $r, r v$ & $\cdot, 9 \leqslant$ & Y,OY & $\cdot, V 4$ & $r, 17$ & $|r|$ & أنثى & 年 \\
\hline$\cdot, \mathrm{V} r$ & r.10 & $\cdot, \wedge$ & $r, \varepsilon \wedge$ & $\cdot, \wedge \wedge$ & $r, r q$ & .,9r & r,OV & $\cdot, \vee \cdot$ & $r, I V$ & $I V \varepsilon$ & الكلي & \\
\hline$\cdot, \mathrm{V} r$ & r,r. & $\cdot, \mathrm{VT}$ & $r, T)$ & $\cdot, V \vee$ & r, 70 & $\cdot, 90$ & $r, \wedge V$ & $\cdot, 79$ & r & TV & أقل من • سنوات & \\
\hline$\cdot, 79$ & r,ir & $\cdot, \vee 9$ & $r, \varepsilon r$ & $\cdot, 9$ & r, ¿. & $\cdot, \wedge \mathrm{V}$ & $r, \leqslant 0$ & $\cdot, \mathrm{V}$. & $r, i r$ & 09 & $1 .-0$ & $\overline{7}$. \\
\hline$\cdot, \mathrm{V} r$ & 1,91 & $\cdot, 91$ & r,rV & $\cdot, \wedge \wedge$ & $r, \cdot 1$ & $\cdot, 10$ & $r, r)$ & $\cdot, 79$ & 1,91 & $\leq \wedge$ & أكثر من · ا سنوات & \\
\hline$\cdot, V r$ & $r, 10$ & $\cdot, \wedge$ & $r, \varepsilon \wedge$ & $\cdot, \wedge \wedge$ & $r, r q$ & $\cdot, 94$ & $r, O V$ & $\cdot, \vee \cdot$ & r,IV & $1 V \varepsilon$ & الكلي & \\
\hline$\cdot, \mathrm{VO}$ & $r, 17$ & $\cdot, \Lambda T$ & $r, 01$ & $\cdot, 9$ & $r, \varepsilon \varepsilon$ & .94 & $r, 7)$ & $\cdot, v_{1}$ & $r, r$. & $1 \leq 9$ & بكالوريوس & $\overline{3}$ \\
\hline$\cdot, 01$ & $r, \cdots$ & $\cdot, \wedge 1$ & r, Yr & $\cdot, \leqslant \vee$ & $1, v \varepsilon$ & $\cdot, \vee \wedge$ & $r, 1 \wedge$ & $\cdot, 00$ & 1,97 & 9 & دبلوم عالي & 3 \\
\hline$\cdot, \uparrow \wedge$ & r,IT & (זד, & $r, \varepsilon$. & $\cdot, \vee Y$ & $r, r \wedge$ & $\cdot, 97$ & $Y, \Sigma ૫$ & $\cdot, 79$ & 1,99 & 17 & ماجستير & q \\
\hline$\cdot, \mathrm{V} r$ & r.10 & $\cdot, \wedge$ & $r, \varepsilon \wedge$ & $\cdot, \wedge \wedge$ & $r, r q$ & $\cdot, 94$ & r,OV & $\cdot, \vee \cdot$ & r,IV & $1 V \varepsilon$ & الكلي & \\
\hline$\cdot, T V$ & $r, I T$ & $\cdot, \wedge$ & $r, \leq 0$ & $\cdot, \lambda r$ & $r, \sum \wedge$ & $\cdot, \wedge 9$ & $r, 0 \leqslant$ & $\cdot, 7$ & $r, i r$ & 79 & أساسية & $\sigma$ \\
\hline$\cdot, \mathrm{V} \vee$ & r, r & $\cdot, \mathrm{Vr}$ & זד, & $\cdot, V Y$ & $r, 01$ & $\cdot$, ג & $r, V \varepsilon$ & $\cdot, \wedge$. & $r, r v$ & $\varepsilon r$ & ثانوية & \\
\hline$\cdot, \vee_{0}$ & $r, \cdot V$ & $\cdot, 10$ & $r, \varepsilon r$ & $\cdot, 99$ & $r, r_{1}$ & $1, \ldots$ & r,o. & $\cdot, V T$ & $r, \cdot \Lambda$ & 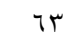 & أساسية وثانوية معا & .3 \\
\hline$\cdot, \mathrm{V} r$ & r.10 & $\cdot, \wedge$ & $r, \varepsilon \wedge$ & $\cdot, \wedge \wedge$ & $r, r q$ & $\cdot, 94$ & r,OV & $\cdot, \vee \cdot$ & r,IV & $1 V \varepsilon$ & الكلي & \\
\hline$\cdot, V Y$ & $r, r \cdot$ & $\cdot, \vee \vee$ & $r, \varepsilon)$ & •, 94 & r,or & $1, \cdot \varepsilon$ & $r, T$. & $\cdot, 71$ & $r, 1 \wedge$ & or & أقل من . . r & $\underline{\underline{y}}$ \\
\hline$\cdot, v_{0}$ & r,Y & $\cdot, \wedge 1$ & r,or & $\cdot, 9$ & r, rA & $\cdot, 91$ & r, r & $\cdot, V T$ & Y,IV & $\varepsilon$ & o... r... & 7 \\
\hline$\cdot, V Y$ & $r, \cdot \wedge$ & $\cdot, \wedge r$ & $r, 01$ & • & $r, r$. & $\cdot, \wedge T$ & r,Or & $\cdot, V_{1}$ & $r, 17$ & Nr & أكثر من ... & \\
\hline$\cdot, \mathrm{VT}$ & $r, 10$ & $\cdot, \wedge$ & $r, \varepsilon \wedge$ & $\cdot, \wedge \wedge$ & $r, r q$ & .,9r & r,OV & $\cdot, \vee \cdot$ & $r, I V$ & $1 V \varepsilon$ & الكلي & \\
\hline
\end{tabular}


ف = 910, · وهي غسير دالة إحصائيا عند هسـتوى $\cdot, \cdot 0$ دلان

ج - نوع المـدرسـة: يتضشح مـن جـدول ع عدم وجـود فـروق دالة

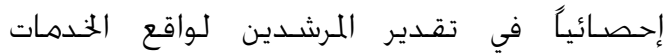

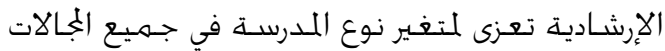

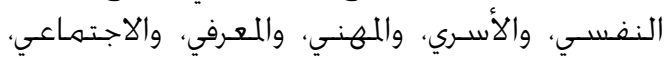

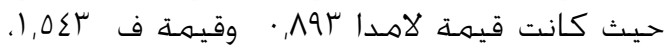

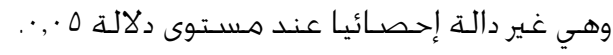
د - عدد الطـلاب: يتضسح هن جـدول ع عدم وجـود فروق

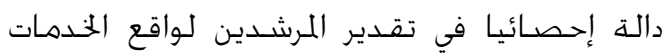

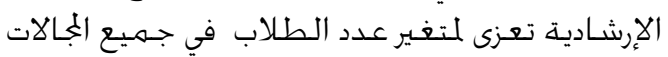

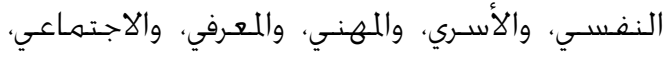

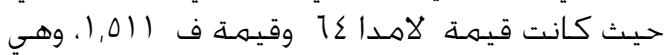

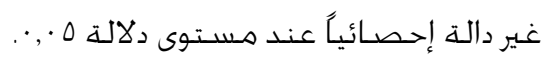

هـ - الخبـــرة: يتضهح هـن جدول ع وجـود فروق دالة

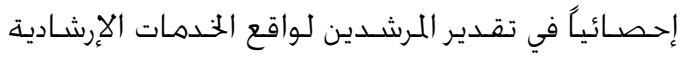

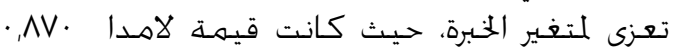

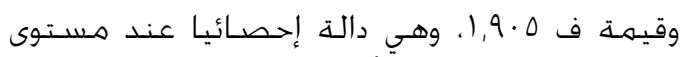

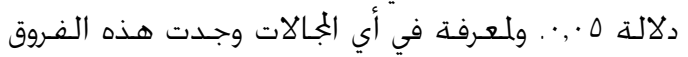

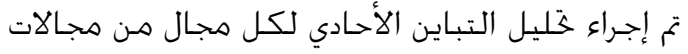

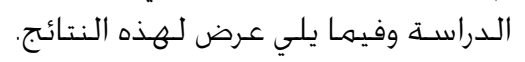

يتضح هن جـدول ه عـدم وجـود فروق دالـة إحصـائيا في تقـدير المرشـدين للخـدمات اللقـدهـة للـموهوبين

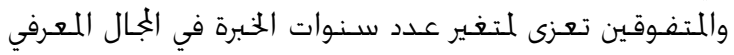
والعُال الاجـتمـاعي.

كمها يتضـح هـن جـدول وجـود فـروق دالة إحصـائيا في

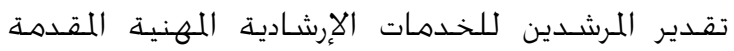

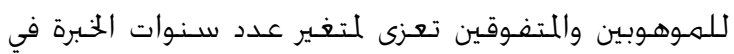

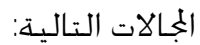

$$
\begin{aligned}
& \text { - النفسـي، حيـث كانت قيمة ف INV, ال، وهي دالة }
\end{aligned}
$$

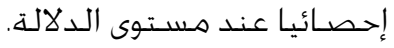

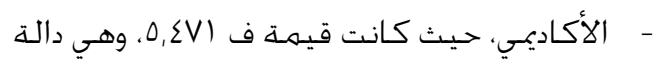

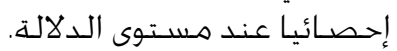

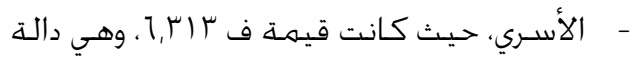

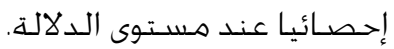

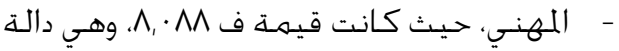

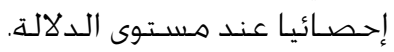

التابعة (MANOVA) للتحقق من دلالة الفروق بين

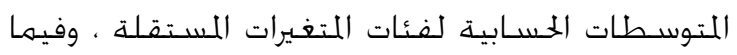

$$
\text { يلي عرض لهذذه النتائج: }
$$

يتضح من جدول r ب وجود فروق ظاهرية بين

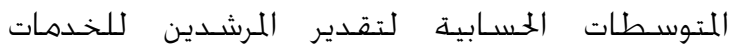

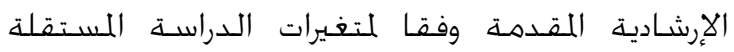

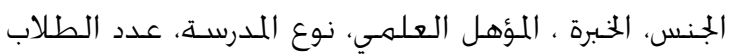

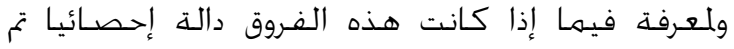

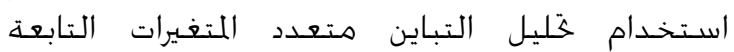
وفيما يلي عرض لهذه النتائج :

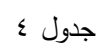

\begin{tabular}{|c|c|c|c|c|c|}
\hline \multicolumn{6}{|c|}{ الدراسة المستقلة } \\
\hline الدلالة & الحربة الخطات & درجات & ف & ل لامدا & المتغير \\
\hline., 079 & 109 & 7 & • & $\cdot, 9 \vee 1$ & الجنس \\
\hline •, OYY & גוr & Ir & $\cdot, 9 Y 0$ & •, & المؤهل \\
\hline$\cdot, 1 \cdot V$ & M & ir & $1,0 \leqslant \pi$ & $\cdot, \wedge 94$ & نوع \\
\hline$\cdot, 111$ & M & ir & 1,011 & $\cdot, \wedge \neg \leq$ & عدد \\
\hline سז., & M & M & $1,9.0$ & $\cdot, \wedge \vee$. & الخبرة \\
\hline
\end{tabular}

نتائج تحليل التباين متعدد المتغيرات التابعة (MANOVA) لالالة الفروق في مستوى الخدمات الإرشادية بين فئات متغير ات

$$
\text { يتضح من جدول ع ما يلي: }
$$

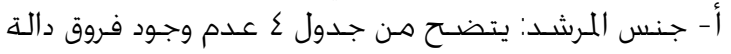

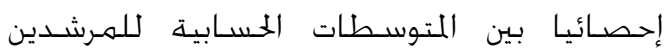

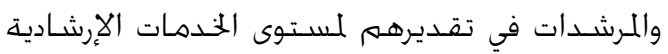

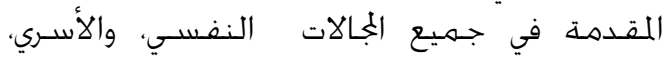

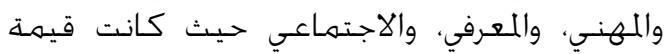

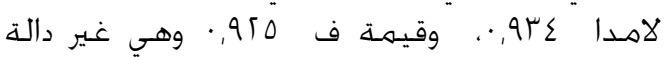
إحصائيا عند مستوى الدلالة فئلة

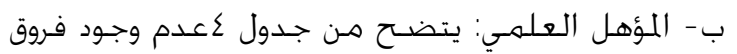

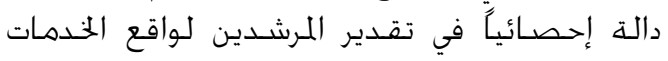

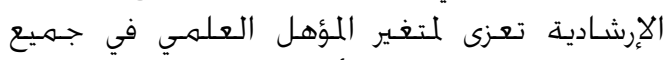

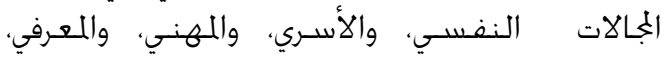

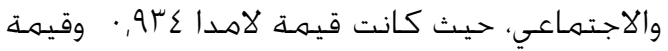


جدول

نتائج تحليل التباين الأحادي لدلالة الفروق بين تقديرات المرشدين للخدمات الإرشادية المقدمة للموهوبين والمتفوقين في المدارس الحكومية وفقا لمتغير سنوات الخبرة

\begin{tabular}{|c|c|c|c|c|c|c|}
\hline مستوى الدلالة & قيمة ف & منوسط المربعات & درجات الحرية & مجموع المربعات & مصدر النباين & المجال \\
\hline \multirow[t]{3}{*}{$\cdot, \cdot r V$} & 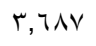 & 1.201 & r & $r, 017$ & الخبرة الخبرة & \\
\hline & & $\cdot, \varepsilon \vee \vee$ & $|v|$ & N1,ork & الخطأ & النفسي \\
\hline & & & IVT & $10, .0 \leqslant$ & الكلي & \\
\hline \multirow[t]{3}{*}{$\cdot, \ldots$} & $0, \sum V 1$ & r,TVV & r & $V, r 00$ & الخبرة الخ & \\
\hline & & $\cdot, T V Y$ & $|v|$ & $11 \leq, 9 \leq V$ & الخطأ & الأكاديمي \\
\hline & & & lVr & Mr,r.r & الكلي & \\
\hline \multirow[t]{3}{*}{$\cdot, \cdot r$} & Tוז, & $0, \cdot 71$ & r & דוזו, & الخبرة الخبرة & \\
\hline & & $\cdot, \lambda \cdot r$ & $|v|$ & ITV,YAT & الخطأ & الأسري \\
\hline & & & IVT & $1 \leqslant \vee, \varepsilon 19$ & الكلي & \\
\hline \multirow[t]{3}{*}{$\cdot, \cdots$} & $\wedge, \cdot \wedge \wedge$ & $0, \vee \vee \vee q$ & r & 11,001 & الخبرة الخبرة & \\
\hline & & $\cdot, \times 10$ & $|v|$ & Irt,IN & الخطأ & المهني \\
\hline & & & IVT & $\mid r r, v \leq 1$ & الكلي & \\
\hline \multirow[t]{3}{*}{$\cdot, Y \backslash V$} & $1,0 \leqslant$. & $\cdot, 991$ & r & 1,911 & الخبرة الخبرة & \\
\hline & & r & $|v|$ & זr.,. 11 & الخطأ & المعرفي \\
\hline & & & IVT & $11 r, .10$ & الكلي & \\
\hline \multirow[t]{3}{*}{$\cdot, \cdot T V$} & r,vor & $1, \varepsilon r_{0}$ & r & $r, \wedge 01$ & 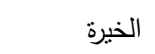 & \\
\hline & & $\cdot, 011$ & $|v|$ & MA,orV & الخطأ & الاجتماعي \\
\hline & & & IVT & $91, \Gamma \wedge \wedge$ & الكلي & \\
\hline
\end{tabular}

ولمعرفة بين أي هـن فئات الخبرة وجـدت هذه الفـروق تم إجراء اختبار شـيفيه للمقفارنات البعدية وفيما يلي عرض لكهذه النتائج.

جدول 1

نتائج اختبار شيفيه للمقارنات البعدية لدلالة الفروق في تقليرات المرشدين بين فئات متغير سنوات الخبرة

\begin{tabular}{|c|c|c|c|c|}
\hline مستوى الدلالة & الخطأ المعياري & الفرق بين المتوسطات & 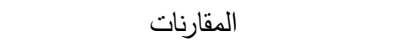 & 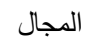 \\
\hline$\cdot$, זт. & $\cdot, 14$ & $\cdot, r \cdot$ & أقل من خمس سنوات * ه ـ. & \\
\hline$*_{\cdot}, \cdot r_{1}$ & . & $\cdot, r_{0}$ & أقل من ه سنوات *أكثر من · ا سنوات & 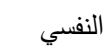 \\
\hline., 07 & rit & $\cdot, 1 \varepsilon$ & ه ... 1 *أكثر من · ( سنوات & \\
\hline$\cdot, 11 \mathrm{r}$ & $\cdot, 10$ & $\cdot, r$ & أقل من خمس سنوات * ه _..1 & \\
\hline$*_{\cdot}, \ldots v$ & $\cdot, 17$ & $\cdot, 0$ & أقل من 0 سنوات *أكثر من · ل سنوات & 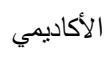 \\
\hline$\cdot, \varepsilon \wedge 9$ & $\cdot, 17$ & $\cdot, 19$ & 0 ـ. 1. & \\
\hline$*_{\cdot, \cdot, r \varepsilon}$ & $\cdot, 17$ & $\cdot, \varepsilon r$ & أقل من خمس سنوات * ه ـ. & \\
\hline$*_{\cdot}, \ldots$ & $\cdot, 1 \mathrm{~V}$ & $\cdot, 07$ & أقل من ه سنوات *أكثر من · ل سنوات & 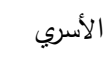 \\
\hline$\cdot, Y Y O$ & $\cdot, 1 \mathrm{~V}$ & $\cdot, 1 \leq$ & 0 ـ. 1 *أكثر من • 1 سنوات & \\
\hline$\cdot, r V \cdot$ & $\cdot, 10$ & $\cdot, r_{0}$ & أقل من خمس سنوات * ه ـ..1 & \\
\hline$*_{\cdot}, \ldots$ & $\cdot, 17$ & $\cdot, 7 \varepsilon$ & أقل من ه سنوات *أكثر من · ـ سنوات & المهني \\
\hline$\cdot, .0 \mathrm{~V}$ & $\cdot, 17$ & $\cdot, \varepsilon$ & 0 ـ. 1 *أكثر من • 1 سنوات & \\
\hline
\end{tabular}

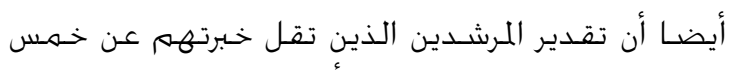

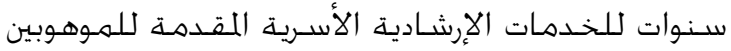

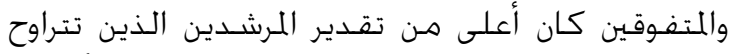

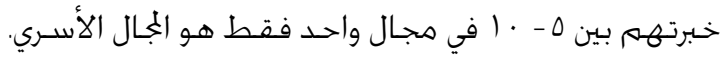

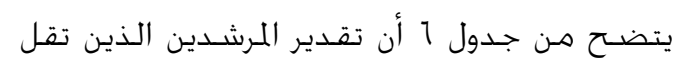

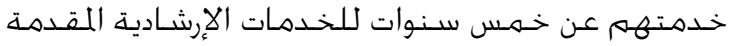

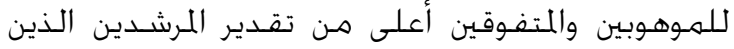

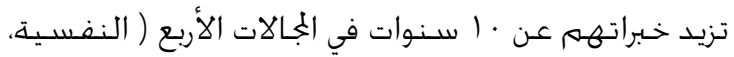

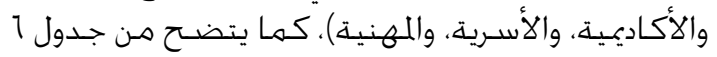


ما يبدو أن الموهوبين والمتفوقين هـن الطلبة يقبلون

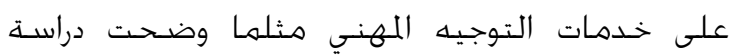
ايشـاك وأبوبكر (Ishak \& Abu Baker, 2010) التي ذكرا

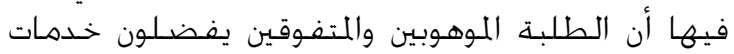

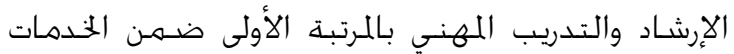

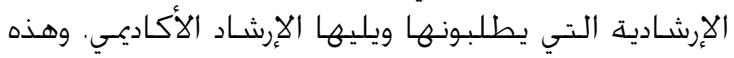

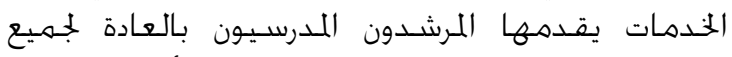

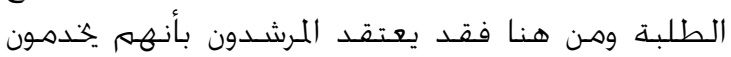

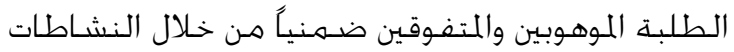

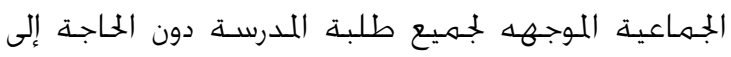

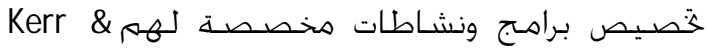

(Sodano, 2003)

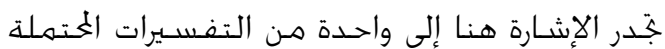

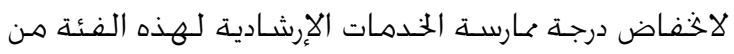

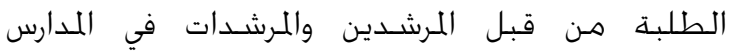

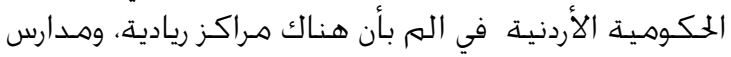

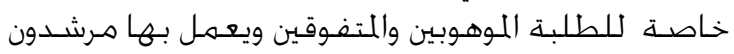

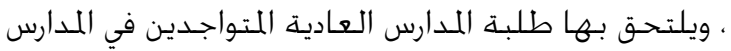

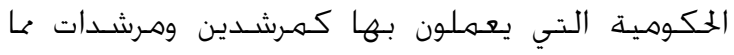
يدفعهمم إلى الاعتماد على تلك المراكز والمدارس في رعاية وخـدمة الطلبة الموهوبين والمتفوقين إرشاديا، وتركيز اهتمام هـرشـدي المدارس العامـة أو الخكوميـة - الذين إلذين

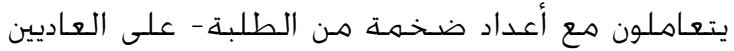

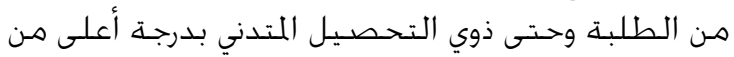

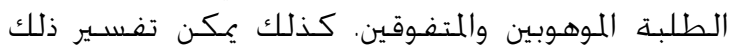

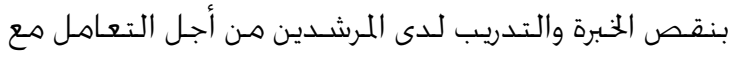

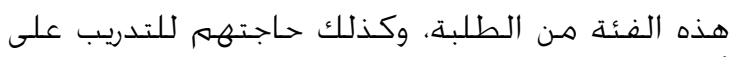

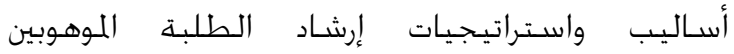
والمتفوقين.

أمها بالنسـبة للسـؤال الثاني والمتعلق بالفـروق في الخدان

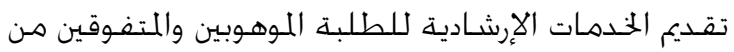

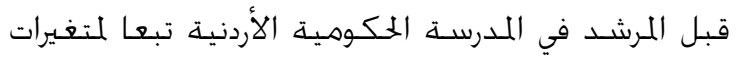

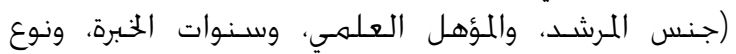

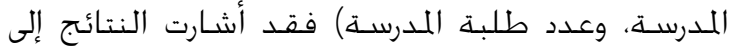

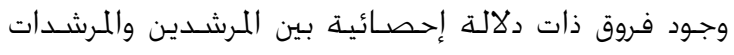

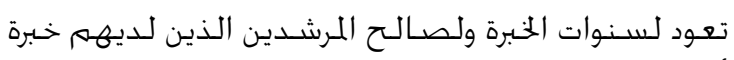
أقل مـن خـمس سـنوات وذلك على الجمالات الفـرعية التالية:

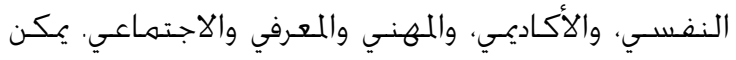

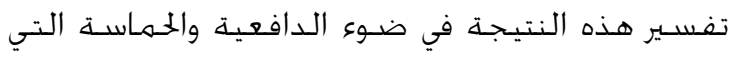

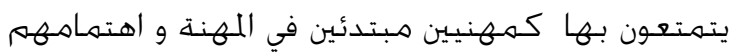

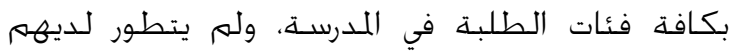

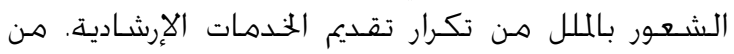
جهة أخرى يمكن تفسير هذه النتيجة في ظل المئ التركيز

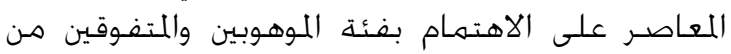

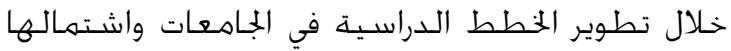

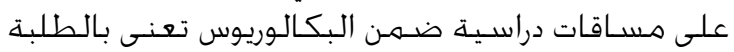

\section{مناقشة النتائج}

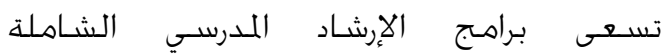
إلى (Comprehensive school counseling programs) الأخـذ بعين الاعتبار حاجات جميع الطلبة في المدرسـة بما

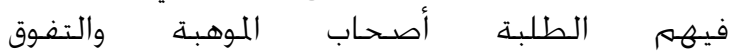
العقلي(Olenchak, 2009)، والذين يدرسـون فيهابها

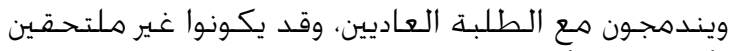

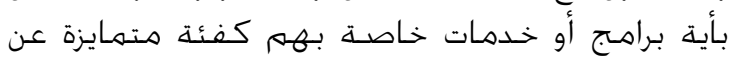
بقية الطلبة مواجهين بذلك ختديات نمائية، وقضايا

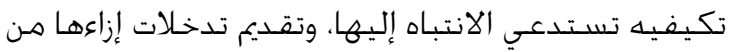

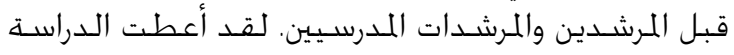

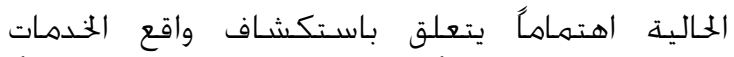

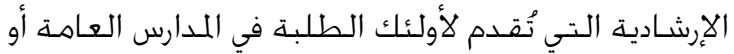

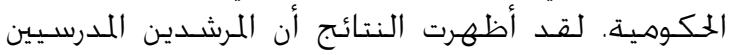

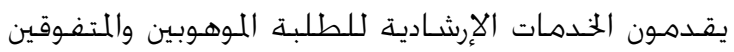

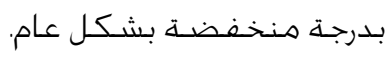

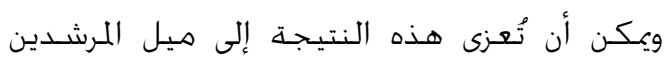

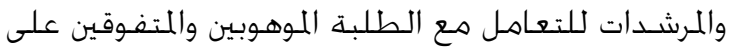

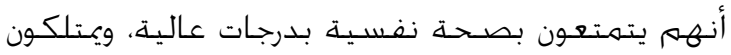

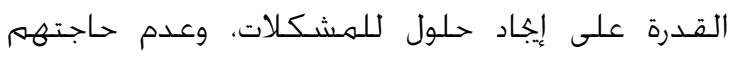

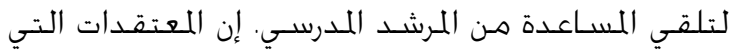

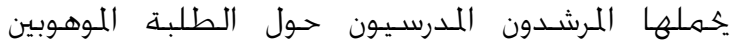

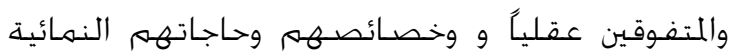

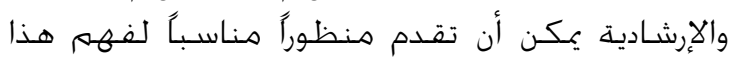

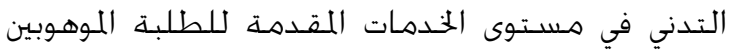

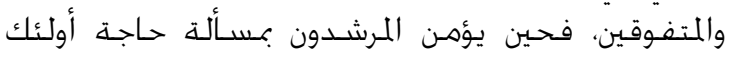

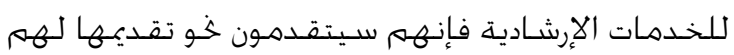

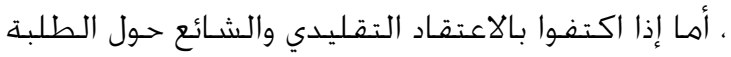

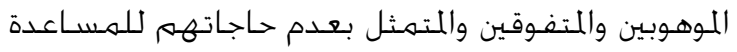

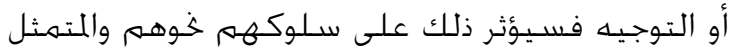

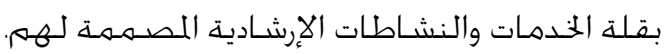
تنسـجم هذه النتيجـة هـ الدراسـة مع ما ذكره

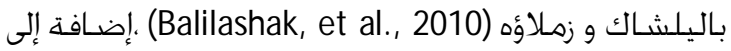

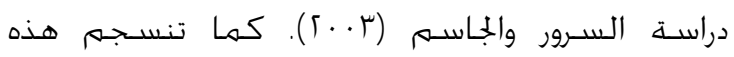

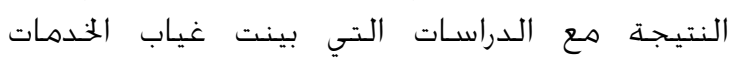

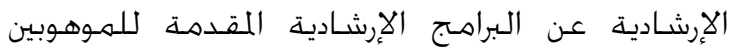

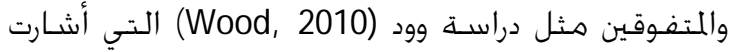

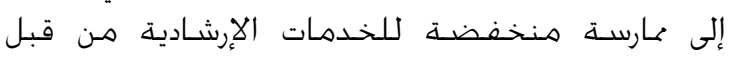

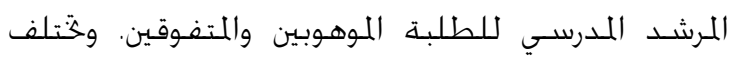

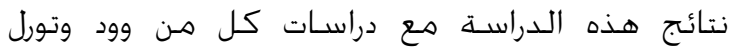

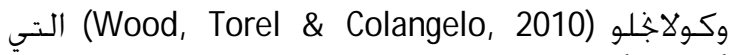

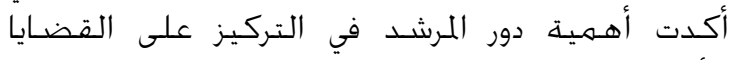

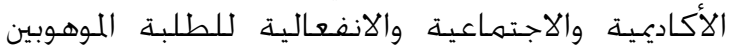
والمتفوقين. 
الموهوبين والمتفوقين ضـهـن المدرسـة العادية، ولتفسير

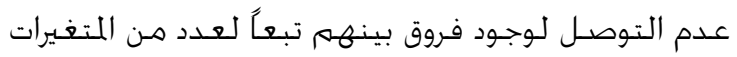

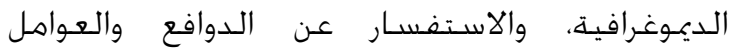

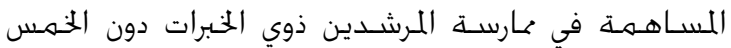

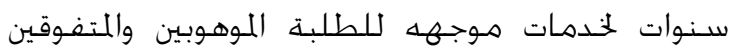
بدرجة أعلى من زملائهـم.

التوصيات والمقترحات:

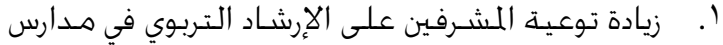

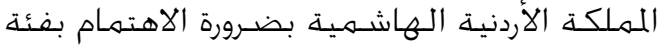

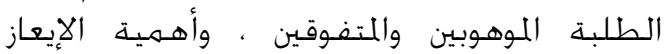

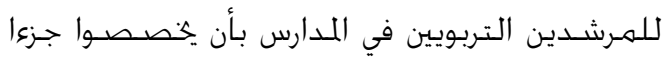

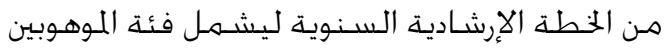

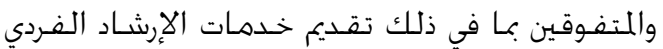

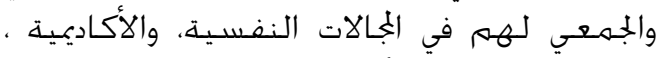

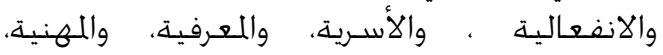
والاجـتماعيتة.

r. ت تدريب المرشـدين التربويين على طرق وأسـاليب إرشـاد الطلبة الموهوبين والمتفوقين في الجبالات النمائية

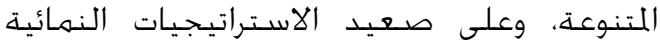
والوقائية والعلاجيـة المتنوعة. r. ضـرورة أن تنبثق الخطط الإرشـادية والبراهـ

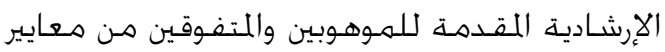

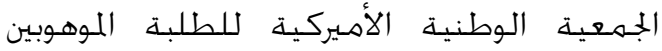
والمتفوقين.

؛. ضـرورة القيام بأبحاث ودراسـات أخـرى جـيدة حول

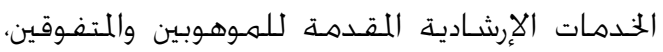

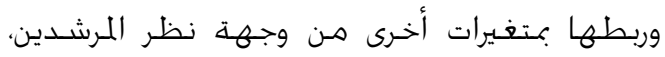
وكذلك مـن وجهة نظر الطلبة الموهوبين والمتفوقين.

\section{المر اجع}

\section{المراجع العربية: - | (اجية}

بنات، سهيلة، وغيث، سـعاد، ومقدادي، يوسف.

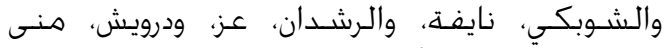

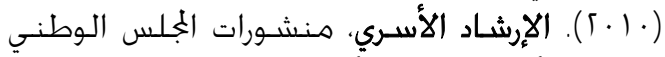
لشـؤون الأسـرة، عمـان، الأردن.

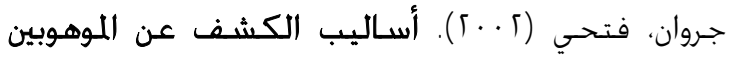
ورعايتهمه عـمّان، الأردن: دار الفكر. الفيال

جروان، فتحي (ع . ؟). الموهبة والإبداع، الأردن: دار الفكر.

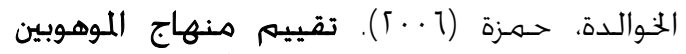

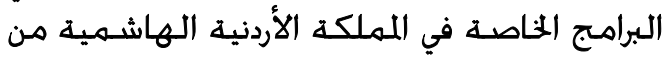

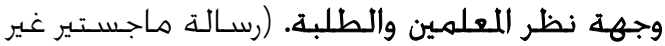

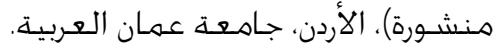

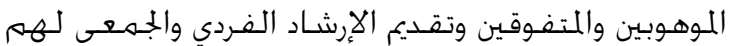

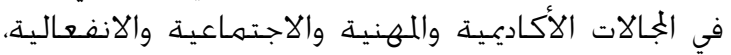

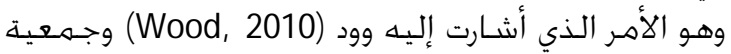

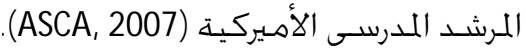

وله تظهر فروق بين المرشـدين والمرشـدات تبعا

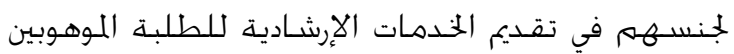

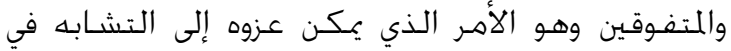

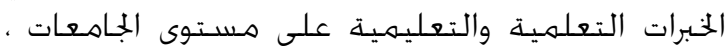

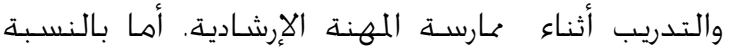

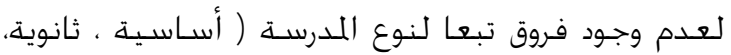

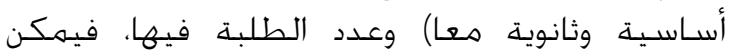

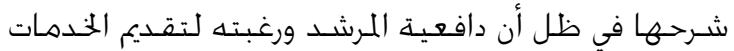

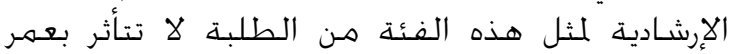

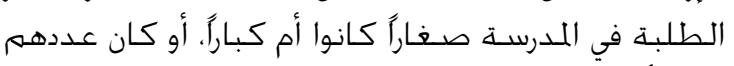
قليلا أو كثيرا.

وفيما يتعلق بالمؤهل العلمي فلم تظهـر فروق دالة

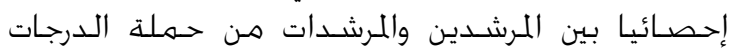

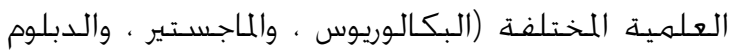

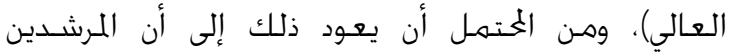

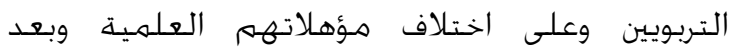

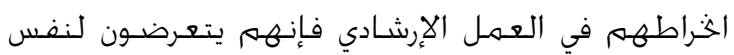

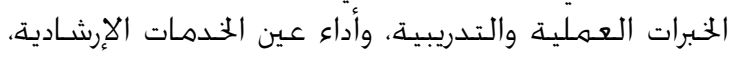

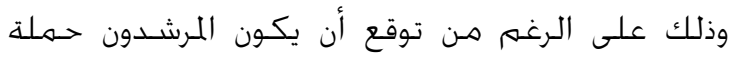

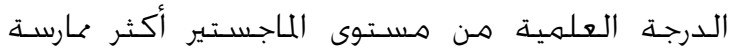

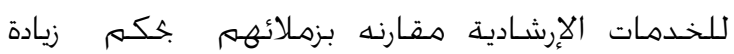

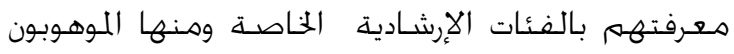
والمتفوقون.

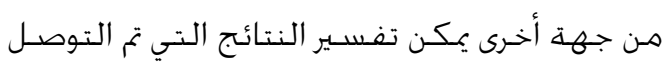

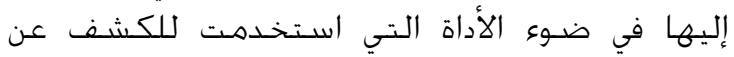

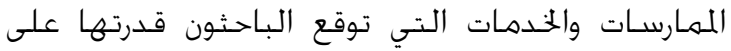

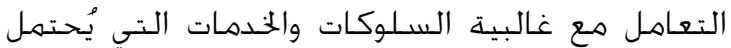

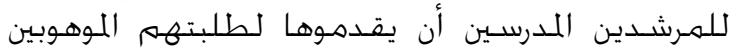

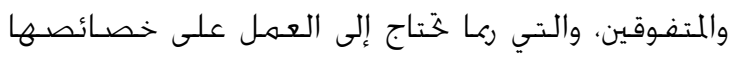

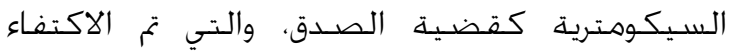

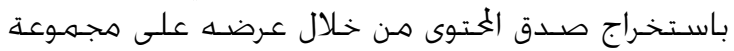

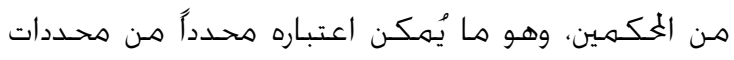

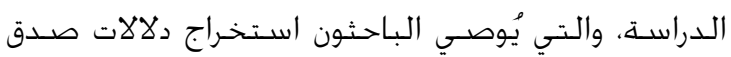

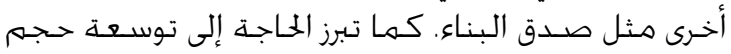

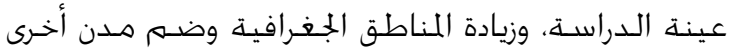

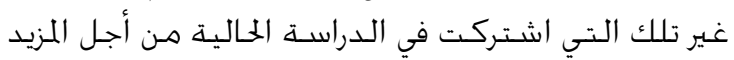

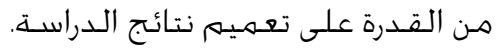

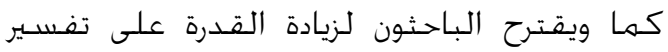

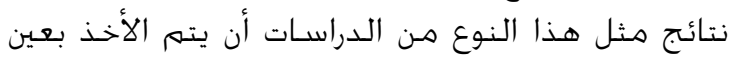

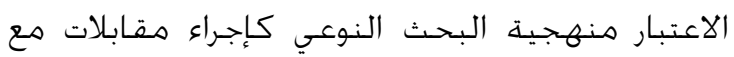

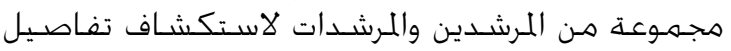

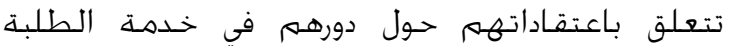




$$
\begin{aligned}
& \text { نظام التعليه في الأردن (ب ( • ؟). مسـترجع بتاريخ }
\end{aligned}
$$

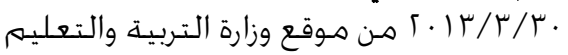

$$
\begin{aligned}
& \text { الأردنية. } \\
& \text { المراجع الاجنبية: - الاجية }
\end{aligned}
$$

American School Counselor Association (ASCA). (2007). Position Statement: Gifted Programs. Retrieved April 14, 2008 fromhtt:/ / asca2.timberlakepublishing.co m/ / files/ PS Gifted. Pdf.

Balilashak ,N., Safavi,M.,\& Mahmoudi ,M.(2010). Comparative Assessment of Mental Health of Gifted \& Average Students of Junior High School. Procedia Social and Behavior Science, 5, 2027-2033.

Colangelo, N. (2002). Counseling Gifted and Talented Students, The National Research Center on the Gifted and Talented. Hoagie Gifted Education Page.

Conyne, R. (2004). Preventive Counseling Helping People to Become Empowered in Systems and Settings (2nd ed.). New York: Taylor and Francis Books. INC

Corey, G. (2005). Theory and Practice of Group Counseling. Brokes/ Cole. Thomson U.S.A.

Davis, G., \& Rimm, S. (1998). Education of the Gifted and Talented. New York : Allyn \& Bacon.

Fleith D., \& Guimarães, S. (2006). Psychoeducational Service for Parents of Gifted and Talented Students: A Brazilian Experience. Gifted Education International, 21, 63- 68. DOI: 10.1177/ 026142940602100109.

Fouladchang ,M. , Kohgard ,A., \& Salah, V.(2010). A study of Psychological Health Among Gifted and Nongifted high schools. Procedia Social and Behavior Science, 5, 1220-1225.

Ishak,N .,\&A bu Baker,A. (2010). Psychological Issues and the Need for Counseling Services Aamong Malaysian Gifted Students. Procedia Social and Behavioral Sciences, 5, 665-673.

Kerr, B., \& Sodano, S. (2003). Career Assessment with Intellectually Gifted Students. Journal of Career A ssessment, 11, 168-

186.

DOI: $10.1177 / 1069072703011002004$.
كوفهمان، فيليبس (1 . ؟). كيف ترعى طفلك الموهوب.

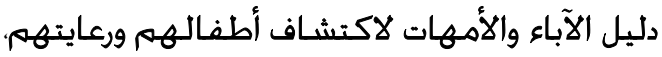

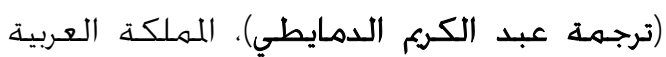
السعودية: دار الزهراء.

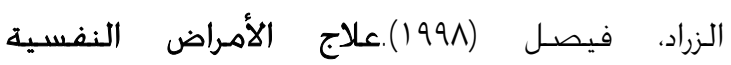
والاضطرابات السلوكية، بيروت: دار العلم للملايين.

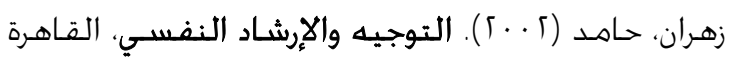

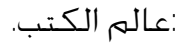

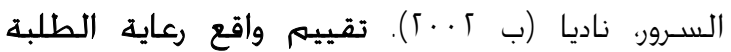
المتميزين والموهوبين في المدارس الحكومية بمملكة البحرين، دراسـة ميدانية، جامعة المبن الخليج.

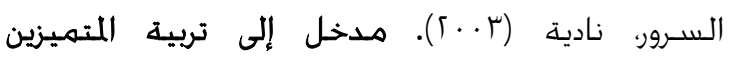
والموهوبين، الطبعة الرابعة، عمان، الأردن: دار الفكر.

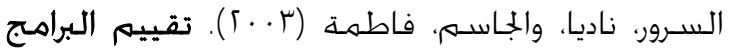
الإثرائية الصيفية (غير التفرغية - إناث)، التقرير الترائ

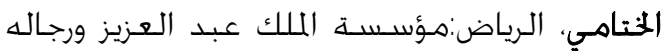

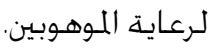

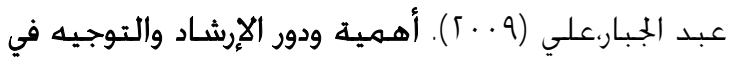

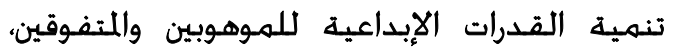
المؤتمر العلمي العربي السادس لرعائ لرعاية الموهوبين

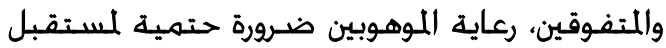

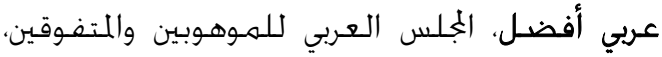

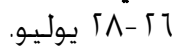

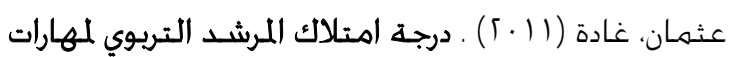

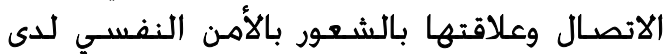
الطلبة، (رسالة ماجستير غير منشـورة) ، الأردن لإن جامعة عمان العربية.

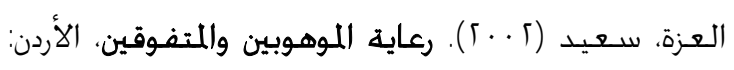
الدار العلمية الدولية ودار الثقافة.

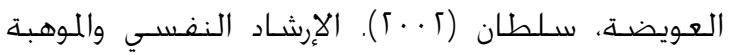

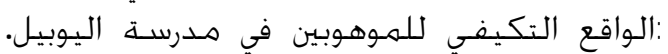

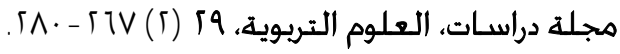

غيث، سعاد، وبنات، سهيلة، وطقش، حنان (9 م. ؟).

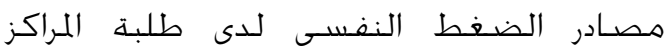

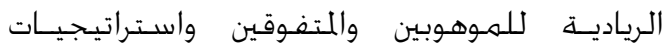

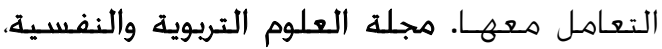
. $1 \Lambda-\left\lceil\sum 1\right.$ (1)).

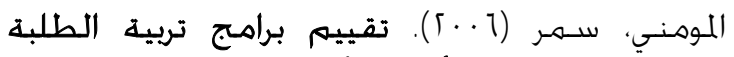

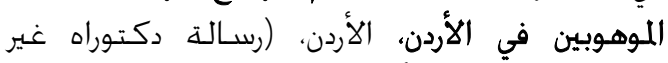
منشـورة)، الجامعة الأردنية.

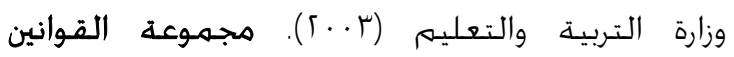
والأنظمة والتعليمات التربيهة، الأردن: الجزء الرابع التعانع 
Olenchak, F. (2009). Effects of Talents Unlimited Counseling on Gifted/ Learning Disabled Students. Gifted Education International, 25, 144 - 164. Perrone, K., Tschopp, M., Snyder, E., Boo, J., \& Hyatt, C. (2010). A Longitudinal Examination of Career Expectations and Outcomes of A cademically Talented Students 10 and 20 Years Post --High School Graduation. Journal of Career Development, 36, 4, 291309. DOI: $10.1177 / 0894845309359347$.

Peterson, J. (2002). Along Student Study of Post-Night school Development in Gifted Individuates at Risk for Poor Educational and Conk. Journal of Secondary Gifted Education, 2, 3, 6-8.,

Peterson, J. S., Duncan, N., \& Canady, K. (2009). A longitudinal study of negative life events, stress, and school experiences of gifted youth. Gifted Child Q uarterly, 53, 34-49.

Peterson, J., \& Lorimer, M.(2011).Student Response to a Small-Group Affective Curriculum in a School for Gifted Children. Gifted Child Quarterly, 55, 167180.

Reis, S. M., \& McCoach, D. B. (2000). The underachievement of gifted students: What do we know and where do we go?. Gifted Child Q uarterly, 44, 3, 152-170.
Silverman, L. (1993). Counseling $\mathrm{N}$ eeds and Program for Gifted. Denver: Love Publishing.

Thomas, V., \& Ray, K. (2006).Counseling exceptional individuals and their families: A systems perspective. Professional School Counseling, 10, 58-65.

Watters, J. (2010). Career Decision Making Among Gifted Students: The Mediation of Teachers. Gifted Child Q uarterly, 54, 3, 222238. DOI: 10.1177/ 0016986210369255.

Whiston, S. C., \& Quinby, R. F. (2009). Review of school counseling outcome research. Psychology in the Schools, 46, 267-272.

Wood, S. (2010). Best Practice in Counseling Acceleration as a program the Gifted in the School: What Really Happen? Gifted Child Q uarterly, 54 (1), 42-58.

Wood, S. Turrell, A., \& Colnagelo, N. (2010). School Counselors Perceptions and Experience With Acceleration as a Program Option for Gifted and Talented Students. Gifted Child Q uarterly, 54 (3), 168 178.

Yoo, J., \& Moon, S. (2006). Counseling Needs of Gifted Students, An Analysis of Intake Forms at $A$ University-Based Counseling Center. Gifted Child Q uarterly, 50 (4), 1, 5261. 